\title{
The effectiveness of exercise-based interventions for preventing or treating postpartum depression: a systematic review and meta-analysis \\ --Manuscript Draft--
}

\begin{tabular}{|c|c|c|}
\hline Manuscript Number: & \multicolumn{2}{|l|}{ AWMH-D-18-00044R2 } \\
\hline Full Title: & \multicolumn{2}{|c|}{$\begin{array}{l}\text { The effectiveness of exercise-based interventions for preventing or treating postpartum } \\
\text { depression: a systematic review and meta-analysis }\end{array}$} \\
\hline Article Type: & \multicolumn{2}{|l|}{ Review Article } \\
\hline Keywords: & \multicolumn{2}{|c|}{ postpartum; depression; exercise; systematic review, meta-analysis } \\
\hline Corresponding Author: & \multicolumn{2}{|l|}{$\begin{array}{l}\text { Tim Carter } \\
\text { UNITED KINGDOM }\end{array}$} \\
\hline \multicolumn{3}{|c|}{$\begin{array}{l}\text { Corresponding Author Secondary } \\
\text { Information: }\end{array}$} \\
\hline \multicolumn{3}{|c|}{ Corresponding Author's Institution: } \\
\hline \multicolumn{3}{|c|}{$\begin{array}{l}\text { Corresponding Author's Secondary } \\
\text { Institution: }\end{array}$} \\
\hline First Author: & \multicolumn{2}{|l|}{ Tim Carter, PhD } \\
\hline \multicolumn{3}{|c|}{ First Author Secondary Information: } \\
\hline \multirow[t]{4}{*}{ Order of Authors: } & \multicolumn{2}{|l|}{ Tim Carter, PhD } \\
\hline & \multicolumn{2}{|l|}{ Anastasios Bastounis, MSc } \\
\hline & \multicolumn{2}{|l|}{ Boliang Guo, PhD } \\
\hline & \multicolumn{2}{|l|}{ Jane C Morrell, PhD } \\
\hline \multicolumn{3}{|c|}{ Order of Authors Secondary Information: } \\
\hline Funding Information: & $\begin{array}{l}\text { Nottingham City Clinical Commissioning } \\
\text { Group's National Institute for Health } \\
\text { Research Capability Funding }\end{array}$ & Dr. Tim Carter \\
\hline Abstract: & \multicolumn{2}{|c|}{$\begin{array}{l}\text { Purpose: Postpartum depression can have detrimental effects on both a mother's } \\
\text { physical and mental health and on her child's growth and emotional development. The } \\
\text { aim of this study is to assess the effectiveness of exercise/physical activity-based } \\
\text { interventions in preventing and treating postpartum depressive symptoms in } \\
\text { primiparous and multiparous women to the end of the postnatal period at } 52 \text { weeks } \\
\text { postpartum. Methods: Electronic databases were searched for published and } \\
\text { unpublished randomised controlled trials of exercise/physical activity-based } \\
\text { interventions in preventing and treating depressive symptoms and increasing health- } \\
\text { related quality of life in women from } 4 \text { to } 52 \text { weeks postpartum. The results of the } \\
\text { studies were meta-analysed and effect sizes with confidence intervals were calculated. } \\
\text { The Grading of Recommendations Assessment and Development and Evaluation } \\
\text { (GRADE) system was used to determine the confidence in the effect estimates. } \\
\text { Results: Eighteen trials conducted across a range of countries met the inclusion } \\
\text { criteria. Most of the exercise interventions were aerobic and coaching compared to } \\
\text { usual care, non-intervention and active controls. Small effect sizes of exercise-based } \\
\text { interventions in reducing depressive symptoms were observed collectively and the } \\
\text { quality of evidence was low across the individual studies. Discussion and conclusions: } \\
\text { Although exercise-based interventions could create an alternative therapeutic } \\
\text { approach for preventing major depression in postpartum women who experience } \\
\text { subthreshold elevated depressive symptoms, the clinical effectiveness and the cost- } \\
\text { effectiveness of exercise-based and physical activity interventions need to be better } \\
\text { established. There is a need for further, more rigorous testing of such interventions in } \\
\text { high-quality randomised controlled trials against active control conditions before large- } \\
\text { scale roll-out of these interventions in clinical practice is proposed. }\end{array}$} \\
\hline
\end{tabular}


Response to Reviewers:
Dear reviewers and the editor,

We have made the remaining minor changes suggested by the reviewers. We also feel the manuscript is now in line with the author guidance.

Kind regards

Tim Carter 
Authors:

Tim Carter $^{1}$, Anastasios Bastounis ${ }^{1}$, Boliang Guo ${ }^{1}$, and C Jane Morrell ${ }^{1}$

Affiliations:

${ }^{1}$ University of Nottingham, United Kingdom

Title:

The effectiveness of exercise-based interventions for preventing or treating postpartum depression: a systematic review and meta-analysis

Corresponding author:

Tim Carter; email: timothy.carter@nottingham.ac.uk; telephone: +44 (0) 11574 84318; ORCID: 0000-0002$1608-5112$

Acknowledgements:

This work was funded by the Nottingham City Clinical Commissioning Group's National Institute for Health Research Capability Funding

Conflict of Interest:

Tim Carter, Anastasios Bastounis, Boliang Guo, and C Jane Morrell declare that they have no conflict of interest. 


\section{Abstract}

Purpose: Postpartum depression can have detrimental effects on both a mother's physical and mental health and on her child's growth and emotional development. The aim of this study is to assess the effectiveness of exercise/physical activity-based interventions in preventing and treating postpartum depressive symptoms in primiparous and multiparous women to the end of the postnatal period at 52 weeks postpartum. Methods: Electronic databases were searched for published and unpublished randomised controlled trials of exercise/physical activity-based interventions in preventing and treating depressive symptoms and increasing health-related quality of life in women from 4 to 52 weeks postpartum. The results of the studies were metaanalysed and effect sizes with confidence intervals were calculated. The Grading of Recommendations Assessment and Development and Evaluation (GRADE) system was used to determine the confidence in the effect estimates. Results: Eighteen trials conducted across a range of countries met the inclusion criteria. Most of the exercise interventions were aerobic and coaching compared to usual care, non-intervention and active controls. Small effect sizes of exercise-based interventions in reducing depressive symptoms were observed collectively and the quality of evidence was low across the individual studies. Discussion and conclusions: Although exercise-based interventions could create an alternative therapeutic approach for preventing major depression in postpartum women who experience subthreshold elevated depressive symptoms, the clinical effectiveness and the cost-effectiveness of exercise-based and physical activity interventions need to be better established. There is a need for further, more rigorous testing of such interventions in high-quality randomised controlled trials against active control conditions before large-scale roll-out of these interventions in clinical practice is proposed.

\section{Introduction}

About $20 \%$ of women globally experience a perinatal mental health disorder, mainly depression and anxiety, when they are pregnant or in the perinatal period up to 52 weeks after they have given birth (WHO 2017). The most severely affected women can develop self-harm and suicidal ideations (Pope et al 2013; Wisner et al 2013). Perinatal anxiety and depression can compromise the long term growth and development of the baby (FaríasAntúnez et al 2017), with long term costs of £8.1bn (Bauer et al 2014). A range of physical, genetic and socioeconomic factors put pregnant and postpartum women at risk of perinatal mental health problems whilst buffering factors (e.g. supportive partner) are protective (Austin et al 2010). 
In the United Kingdom early psychosocial or pharmacological interventions are recommended to reduce the prevalence of perinatal anxiety and depression, to benefit women and families, and reduce costs (Morrell et al 2009; NICE 2014; Morrell et al 2016; Saligheh et al 2017).

The perinatal period is also characterised by difficulty in managing weight and engaging in physical activity (Gaston \& Cramp 2013). A reduction in physical activity/exercise throughout pregnancy can lead to lower selfratings of quality of life (Campolong 2017) and can have detrimental effects on physical health (Fazzi, Saunders, Linton, Norman, \& Reynolds 2017). Sedentary behaviours have been associated with increased risk for postnatal depressive symptoms, whereas physical activity in pregnancy and postnatally has been associated with decreased risk for developing depressive symptoms (Claesson, Klein, Sydsjo, \& Josefsson 2014; Teychenne \& York 2013). Given that engaging in sedentary behaviours during pregnancy can be continued postpartum, exercise-based interventions could yield multi-tiered benefits for the physical and mental health of perinatal women.

Small to moderate effects on depression symptoms have been found from exercise-based interventions in adults and young people (Standardised Mean Difference [SMD] -0.62, 95\% Confidence Interval [CI] -0.81, -0.42), compared to control conditions (Cooney et al 2013; Carter et al 2016). In postpartum populations, there is a promising evidence base for exercise-based interventions in preventing and treating depressive symptoms (McCurdy et al 2017; Poyatos-León et al 2017). The content of these interventions covers aerobic activities, stretching, yoga and exercise-based coaching. In randomised controlled trials (RCTs), exercise-based interventions have been compared to control conditions of usual care (UC) or non-intervention (NI), but few have been compared against active control (AC) or wait list control (WLC) (Armstrong \& Edwards 2004; LeCheminant et al 2014). Most exercise-based interventions have been tested in targeted populations, such as women with elevated depression symptoms (Buttner et al 2015) or women with a previous history of depression (Lewis et al 2014).

There is now a need for a robust evidence synthesis that follows methodologically rigorous processes (Saligheh et al 2017) to systematically identify the components and characteristics of interventions, and analyse their effectiveness, to promote the development of beneficial exercise-based interventions in clinical practice (Saligheh et al 2017). 
63 This review aims to synthesise evidence from randomised controlled trials (RCTs) for the clinical effectiveness

64 of exercise-based interventions compared to all types of control in preventing and treating depressive symptoms

65 in primiparous and multiparous women from the possible onset at 4-6 weeks postnatally (Putman et al 2017), to the end of the postpartum period (12 months after the birth of the baby). Additionally, this review aims to identify factors associated with the effectiveness of exercise-based interventions, testing the moderating effects of the intervention's: scope (universal vs. targeted); content (strongly exercise-oriented vs. exercise consulting and coaching); duration (short vs. long duration); and control condition: active control (AC) vs. usual care (UC), nonintervention (NI), and wait list control (WLC).

\section{Methods}

The protocol of this systematic review and meta-analysis was registered with PROSPERO (2017:CRD42017068376) and the presentation of the findings conforms to PRISMA (Moher et al 2009). The primary outcome was depression symptoms in postpartum women at post intervention and the secondary outcomes were symptoms of anxiety and health-related quality of life (HRQoL).

\section{Inclusion criteria:}

Population: primiparous or multiparous postnatal women.

Intervention: exercise-based (supervised, unsupervised, coaching-based, motivational, behavioural-oriented, universal, targeted or treatment based, in a community or clinical context).

Comparison: any type of control condition (e.g. flexibility/stretching or social support sessions, UC, NI, AC, WLC).

Outcomes: depression symptoms using a validated assessment tool (e.g. Edinburgh Postnatal Depression Scale (EPDS), Patient Health Questionnaire).

Study type: published or unpublished individual RCTs or cluster RCTs.

\section{Exclusion criteria:}

Population: pregnant women; women with psychiatric diagnoses other than depression.

Intervention: no details of the exercise component; intervention delivered before 4 weeks or after 52 weeks.

Comparison: no comparison interventions were excluded. 
92

93

94

95

96

97

98

99

100

101

102

103

104

105

106

107

108

109

110

111

112

113

114

115

116

117

118

119

120

Outcomes: no depression symptom measure; outcomes before 4 weeks postpartum.

Study type: non RCTs.

Search Strategy

Libraries and databases searched for papers published between 1974 and June 2017 were: Allied and Complementary Medicine Database (AMED), Applied Social Sciences Index and Abstracts (ASSIA), Cumulative Index to Nursing and Allied Health Literature (CINAHL), Current Controlled Trials, EMBASE (Excerpta Medica), ISRCTN Register, MEDLINE (including PubMed), National Institute for Health Research Health Technology Assessment (NIHR HTA) programme databases, PROSPERO, PsycINFO, Scopus, Science Citation Index and Conference Proceedings (Web of Science), The Cochrane Library (Cochrane Database of Systematic Reviews, Database of Abstracts of Reviews of Effects, Cochrane Central Register of Controlled Trials), World Health Organisation's International Clinical Trials Registry Platform (ICTRP). Online databases of grey literature searched, were: clinicaltrials.gov, International Standard Randomised Controlled Trials Number (ISRCTN) Register, OpenGrey, and ProQuest Dissertations \& Theses (PQDT).

The search strategy incorporated Medical Subject Heading (MeSH) terms in five areas:

Population: Postpartum Period; and Pregnant women/ OR Postnatal care/ OR Perinatal care. Depression/ OR Depression, Postpartum/; Anxiety/ OR Anxiety Disorders/

Intervention: Exercise Test/ OR Exercise/ OR Exercise Therapy/ OR Exercise Movement Techniques/

Outcome: Depression/ OR Depression, Postpartum/; Anxiety/ OR Anxiety Disorders/

Study type: The search was optimised using the 'RCTs (plus cluster)' clinical search filter recommended by the Centre for Reviews and Dissemination (CRD 2009).

Hand-searches of public online databases and contacts with field experts were also conducted. Three syntax sets were used in combination with the MeSH terms above for searching Medline, EMBASE and PsycINFO (See Table 1). 
Relevant authors were contacted when: full text articles were not available; there was insufficient information

122

123

124

125

126

127

128

129

130

131

132

133

134

135

136

137

138

139

140

141

142

143

144

145

146

147

148 provided for the inclusion criteria to be applied; there were insufficient details reported on the outcomes. Lack of reply from authors led to one study being included only in the qualitative synthesis: (LeCheminant et al 2014).

Following initial screening of titles and abstracts, full texts of all potentially relevant studies were assessed for inclusion independently by two reviewers (TC \& AB). Disagreements were resolved by discussion, or a third reviewer (JM) was consulted. Reference lists of included articles were searched for potentially eligible studies.

\section{Data Extraction}

Adapted versions of the Effective Practice and Organisation of Care (EPOC) Review Group data abstraction form and the Cochrane Collaboration Form for extracting data from RCTs were used to extract data from included studies. Two reviewers (TC \& AB) extracted data independently and disagreements were resolved by discussion between the two reviewers who presented their arguments to each other until agreement was made. A third reviewer (JM) would have been the final arbiter, but this process was not required at any point in this review. Extracted data included information on: study authors, participant demographic characteristics, intervention and control conditions, study method, recruitment and completion rates, outcomes and measurement times, information for assessment of risk of bias and quality. Experimental conditions were coded as either (a) intervention: exercise or physical activity, yoga, coaching sessions with exercise, social support with exercise or (b) control: UC, AC (social support sessions) NI, WLC.

\section{Quality assessment}

The quality of included studies was assessed using the Cochrane Collaboration tool for assessing risk of bias (Higgins et al 2011). Within each specified domain, adequate reporting resulted in a rating of low risk of bias, whereas evidence of bias resulted in a rating of high risk of bias. When insufficient detail was reported for clear assessment, a rating of unclear risk of bias was given. There was also an assessment of any additional threats of bias. Two researchers (TC \& AB) independently rated the risk of bias for each included study. Any disagreements were resolved after discussion. The Grading of Recommendations Assessment and Development and Evaluation (GRADE) system was used to assess confidence in the quality of evidence of individual outcomes and the strength of recommendations (Guyatt et al 2008). 
Data analysis was performed using RevMan Version 5.3 (Nordic Cochrane Centre 2014) and STATA Version 14

153 (StataCorp 2015). Standardised mean differences were computed for all included studies. Post-intervention effect sizes were computed, comparing the intervention arms of the studies to all types of control. Mean differences in the primary outcome (depression symptoms) were computed to Hedge's g. Hedge's g was obtained by subtracting control mean by intervention mean, divided by their pooled standard deviation and implementing the correction factor J (Borenstein et al 2009). Given the heterogeneity of methodologically diverse studies, a random effects model was adopted. Four subgroup analyses were pre-planned and conducted: 1) universal vs targeted interventions; 2) active exercise-orientated interventions vs non-active exercise-orientated; 3) studies using active control groups vs studies using other control groups; 4) interventions of longer duration vs interventions of shorter duration.

\section{Results}

The search yielded 20,671 abstracts following the removal of duplicates. Screening of title and abstracts resulted in 103 full texts articles undergoing eligibility assessment, of which 18 were included in the review, and 17 in the meta-analysis. Figure 1 presents a PRISMA Flow Chart illustrating study selection.

\section{Insert Figure 1}

Table 2 presents a summary of the 18 studies included in the qualitative synthesis. Seventeen studies were included in the meta-analysis: three each from Australia (Armstrong \& Edwards 2003; Armstrong \& Edwards 2004; Norman et al 2010), and the UK (Daley et al 2008; Daley et al 2015; Forsyth et al 2017), six from the USA (Buttner et al 2015; Keller et al 2014; Lewis et al 2014; Robichaud et al 2009; Shelton et al 2015; Surkan et al 2012), one each from Canada (DaCosta et al 2009), Japan (Haruna et al 2013), Iran (Saeedi 2013), Taiwan (Yang \& Chen 2017), and India (Thiruppathi et al 2014). 

(Armstrong \& Edwards 2003; Daley et al 2008; Forsyth et al 2017; Shelton 2015; Yang \& Chen 2017). The number of participants ranged from 20 to 160; whilst one study had 679 participants. Apart from two included theses (Robichaud et al 2009; Shelton 2015), the studies were published in peer reviewed academic journals.

A targeted prevention approach was used in 10 studies, to target at-risk women with a history of depression or elevated depression symptoms (Armstrong \& Edwards 2003; Armstrong \& Edwards 2004; Buttner et al 2015; DaCosta et al 2009; Daley et al 2008; Lewis et al 2014; Robichaud et al 2009; Saeedi 2013). A universal prevention approach (targeted at a whole population that has not been identified on the basis of individual risk) was tested in eight studies (Haruna et al 2013; Keller et al 2014; Norman et al 2010; Shelton et al 2015; Thiruppathi et al 2014; Yang \& Chen 2017). Two studies tested a treatment approach for women with postpartum depression (Daley et al 2015; Forsyth et al 2017).

192

In six studies, participants' baseline depression symptoms were mild (Keller et al 2014; Lewis et al 2014; Norman et al 2010; Shelton et al 2015; Thiruppathi et al 2014; Yang \& Chen 2017). In two studies participants' symptoms were mild to moderate (Buttner et al. 2015; DaCosta et al. 2009); in five studies, symptoms were moderate (Armstrong \& Edwards 2003; Armstrong \& Edwards 2004; Daley et al 2015; Forsyth et al 2017; Surkan et al 2012), and in three studies symptoms were moderate to severe (Daley et al 2008; Robichaud et al 2009; Saaei 2013).

\section{Intervention and control conditions}

201

Most studies compared the intervention arm to a NI or UC control condition, with four studies using an AC comparison (Armstrong \& Edwards 2004; Keller et al 2014; LeCheminant et al 2014; Lewis et al 2014). See Table 3 for an overview of intervention characteristics in each study.

In eight studies, the interventions tested were of aerobic and/or strengthening and/or muscle stretching content (Armstrong \& Edwards 2004; Buttner et al 2015; Haruna et al 2013; LeCheminant et al 2014; Robichaud 2009; Saaedi 2013; Shelton 2015; Yang \& Chen 2017). In four studies the content was coaching and motivational health promotion techniques and no exercise (Daley et al 2015; Daley et al 2008; Lewis et al 2014; Surkan et al 2012). 
techniques (Armstrong \& Edwards 2003; DaCosta et al 2009; Forsyth et al 2017; Keller et al 2014; Norman et al 2010; Thirrupathi et al 2014).

The duration of $76 \%$ (13/17) interventions was up to 12 weeks; with four studies testing interventions for longer than 12 weeks (Daley et al 2015; LeCheminant et al 2014; Lewis et al 2014; Surkan et al 2012). The duration of the supervised delivered sessions ranged from 30 to 90 minutes, with most sessions delivered at moderate intensity. The frequency of the sessions delivered per week across the interventions ranged from one to four.

Six studies were of supervised interventions (Armstrong \& Edwards 2003; Haruna et al 2013; Keller et al 2014; Norman et al 2010; Saeedi 2013; Thiruppathi et al 2014); seven studies were of non-supervised interventions (Daley et al 2015; Daley et al 2008; Lewis et al 2014; Robichaud 2009; Shelton 2015; Surkan et al 2012; Yang \& Chen 2017); and five studies were of both supervised and non-supervised elements (Armstrong \& Edwards 2004; Buttner et al 2015; DaCosta et al 2009; Forsyth et al 2017; LeCheminant et al 2014).

Of the supervised interventions six were delivered by qualified service providers (Buttner et al 2014; DaCosta et al 2009; Haruna et al 2013; LeCheminant et al 2014; Norman et al 2010; Thiruppathi et al 2014); four were delivered by non-qualified service providers (Armstrong \& Edwards 2003; Armstrong \& Edwards 2004; Keller et al 2014; Saeedi et al 2013); and one did not report provider information (Forsyth et al 2017). Table 3 presents an overview of intervention characteristics for each study.

\section{Insert Table 3}

Outcomes

Depression symptoms were assessed using the EPDS in most studies. Two studies used the The Center for Epidemiological Studies-Depression (CES-D) (Surkan et al 2012; LeCheminant et al 2014) and one study used the Hamilton Rating Scale for Depression (HRSD) (Buttner et al 2015). HRQoL was measured in three studies using the 36-Item Short-Form Health Survey (Buttner et al 2015; Daley et al 2015; Haruna et al 2013) and anxiety 2015). 
241 Figure 2 presents the ratings for each item of the risk of bias assessment tool. Overall, most of the RCTs were of 242 low to moderate quality. "Other risk of bias" was identified in multiple studies and was caused by: i. uncertainty about ITT analysis in five studies (Daley et al 2008; Norman et al 2010; Thiruppathi et al 2014; Yang \& Chen 2017) and ii. potential threat of unsuccessful randomisation in one study (Daley et al 2015). "Unclear risk of bias" was identified in multiple studies caused by: i. insufficient details of the allocation concealment procedures and ii. insufficient details regarding the sequence generation methods (five studies). There was poor reporting of the outcomes in two of the studies (Saeedi 2013; Thirrupathi et al 2014) leading to a rating of high risk of bias. Given the nature of intervention and control conditions, a complete blinding procedure was impossible, however, given the outcome was self-report in most of the studies, they were generally rated as low-risk in the "blinding" sections of the risk of bias tool. Studies that reported an intention-to-treat analysis were rated as low-risk of bias (Higgins et al 2011).

Insert Figure 2

Meta-analysis

A moderate, significant, standardised mean difference (SMD), favouring the intervention condition, was found for depressive symptoms, SMD $=-0.64,95 \% \mathrm{CI}=[-0.96,-0.33], \mathrm{p}<0.001$ (see Figure 3 for forest plot including all studies and the bias-adjusted Hedge's g effect sizes). A non-significant SMD, favouring the intervention condition, was found for secondary outcomes: physical function, $\mathrm{SMD}=-0.04,95 \% \mathrm{CI}=[-0.33,0.26], \mathrm{p}=0.81$; and a non-significant SMD, favouring the control condition, was found for mental function, SMD $=0.27,95 \% \mathrm{CI}$ $=[-0.03,0.56], \mathrm{p}=0.07$. Due to the dearth of data, effect sizes for anxiety were not calculated.

\section{Insert Figure 3}

Sensitivity analyses

Results of the sensitivity analyses showed a small, significant effect on depression, favouring the intervention condition, $\mathrm{SMD}=-0.30,95 \% \mathrm{CI}=[-0.45,-0.15], \mathrm{p}<0.001$ (Armstrong \& Edwards 2004; Buttner et al 2015; DaCosta et al 2009; Daley et al 2008; Daley et al 2015; Forsyth et al 2017; Haruna et al 2013; Lewis et al 2014; 
of the exercise-based interventions after removing the two outlying studies (Saaedi 2013; Thirrupathi et al 2014). This post-hoc sensitivity analysis yielded small, significant, results $(\mathrm{SMD}=-0.25,95 \% \mathrm{CI}=[-0.39,-0.11], \mathrm{p}=$ 0.0005) (see Figure 5).

\section{Insert Figure 4 and Figure 5}

\section{Subgroup analyses}

A comparison of the effectiveness of universal prevention interventions (Haruna et al 2013; Keller et al 2014; Norman et al 2010; Shelton 2015; Surkan et al 2012; Thiruppathi et al 2014; Yang \& Chen 2017) versus targeted prevention or treatment interventions (Armstrong \& Edwards 2003; Armstrong \& Edwards 2004; Buttner et al 2015; DaCosta et al 2009; Daley et al 2008; Daley et al 2015; Forsyth et al 2017; Lewis et al 2014; Robichaud 2009; Saeedi 2013) was conducted. Targeted prevention or treatment interventions yielded a greater effect size compared to universal prevention interventions $(\mathrm{SMD}=-0.75,95 \% \mathrm{CI}=[-1.22,-0.28], \mathrm{p}=0.002$ for the targeted interventions and SMD $=-0.52,95 \% \mathrm{CI}=[-0.99,-0.05], \mathrm{p}=0.03$ for universal prevention interventions) (See Figure 6).

A comparison of the effectiveness of interventions with an active exercise-oriented component (Armstrong \& Edwards 2003; Armstrong \& Edwards 2004; Buttner et al 2015; DaCosta et al 2009; Haruna et al 2013; Norman et al 2010; Robichaud 2009; Saeedi 2013; Shelton 2015; Thiruppathi et al 2014) versus those with coaching/motivational components (Daley et al 2008; Daley et al 2015; Forsyth et al 2017; Keller et al 2014; Lewis et al 2014; Surkan et al 2012; Yang \& Chen 2017) was conducted. Interventions with active exerciseoriented components yielded larger effects than those with coaching/motivational components $(\mathrm{SMD}=-1.19$, $95 \% \mathrm{CI}=[-1.84,-0.53], \mathrm{p}=0.0004$ for active exercise interventions and $\mathrm{SMD}=-0.21,95 \% \mathrm{CI}=[-0.37,-0.05]$ $\mathrm{p}=0.009$ for coaching/motivational interventions (See Figure 7).

(1)

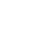



$95 \% \mathrm{CI}=[-1.09,-0.32], \mathrm{p}=0.0003)($ See Figure 8$)$.

\section{Insert Figure 8}

305

A comparison of interventions with long duration (12 weeks or more) versus interventions with a shorter duration (fewer than 12 weeks) was conducted. Interventions with shorter duration (SMD $=-1.72,95 \% \mathrm{CI}=[-3.05,-0.39]$, $p=0.01)$, yielded a larger effect sizes than those of longer duration $(\mathrm{SMD}=-0.52,95 \% \mathrm{CI}=[-0.84,-0.19], \mathrm{p}=$ 0.002) A meta-regression for the effect of duration on effect sizes of these interventions was performed with no significant results $(\beta=0.07,95 \% \mathrm{CI}=[-0.11,0.25], \mathrm{p}=0.415)($ See Figure 9).

Heterogeneity

Heterogeneity was high in the main analysis $\left(\mathrm{I}^{2}=86 \%\right.$, Tau $\left.{ }^{2}=0.33, \mathrm{df}=16, \mathrm{p}<0.0001\right)$ but was eliminated in the sensitivity analysis $\left(\mathrm{I}^{2}=0 \%, \mathrm{Tau}^{2}=0, \mathrm{df}=9, \mathrm{p}=0.59\right)$ where studies with no clear reporting of randomisation procedure were excluded.

\section{Publication bias}

Inspection of the funnel plot for the main analysis revealed extensive asymmetry (see Figure 10 and Figure 11 for the funnel plot and the contour-enhanced funnel plot), indicating potential threat for publication bias. An Egger's test was performed (Egger et al 1997) for testing the funnel plot's asymmetry, indicating statistically significant results for small-study effects $(\beta=-4.72,95 \% \mathrm{CI}=[-5.44,-4.00], \mathrm{p}=0.000)$. However, after the two outlier studies were excluded, the Egger's test did not retain statistical significance $(\beta=-0.08,95 \% \mathrm{CI}=[-0.29,0.45], \mathrm{p}$ $=0.647)$.

\section{Insert Figure 10 and Figure 11}


Due to the dearth of data on secondary outcomes, the quality of evidence was assessed only for the primary outcome. Table 4 is a summary of findings ( $\mathrm{SoF}$ ) table that presents the comparison between exercise/physical activity-based interventions against all types of controls (AC, NI, UC, WL) in reducing depression symptoms. SMD is re-expressed as Mean Difference (MD) using a familiar instrument, the EPDS, in order to facilitate clinical interpretation (Ryan, Sontensso, \& Hill 2016; Schunemann et al 2008). To do so, a pooled standard deviation for EPDS scores was obtained from a cluster RCT (Morrell et al 2009) in order to transform SMD to MD. A small to moderate effect of exercise-based interventions to reduce depressive symptoms was found. We did not downgrade the quality of evidence regarding publication bias, given that the Egger test was non-significant after removing the two outlier studies (Saeedi 2013; Thirruppathi et al 2014). However, since 76\% (13/17) of the studies did not report a clear allocation concealment method, $41 \%$ (7/17) studies reported inadequate methods for sequence generation, and it was unclear whether some of the studies followed an ITT analysis, the quality of evidence was downgraded one level in the risk of bias section. In addition, the confidence intervals in most of the studies crosses \pm 0.50 , leading to the downgrading of the quality of evidence regarding the imprecision of effects (Ryan \& Hill 2016). The downgrading of the evidence was undertaken in accordance with established guidance (see Balshem et al 2011). Consequently, the downgrading in two categories led to a low rating of the quality of evidence regarding the effectiveness of exercise-based interventions in reducing depression symptoms in postpartum women (Ryan \& Hill 2016). Additionally, the transformation of SMD to MD, using a population-based SD for EPDS scores, highlighted that this mean difference does not signify a clinically significant difference (Matthey 2004). In summary, our confidence in the effect estimate for depression symptoms is limited: The true effect may be substantially different from the estimate of the effect.

\section{Insert Table 4}

\section{Discussion}

This meta-analysis found a statistically significant moderate treatment effect ( $\mathrm{SMD}=-0.64)$ of exercise over control conditions for depression symptoms in postpartum women up to 52 weeks after childbirth. Due to high levels of heterogeneity $\left(I^{2}=86 \%\right)$, a sensitivity analysis was conducted excluding the studies with a high risk of bias. This analysis eliminated heterogeneity, however reduced the magnitude of effect to small $(\mathrm{SMD}=-0.30)$, suggesting a consistent yet reduced effect of exercise for depression symptoms in postpartum women. 
As the postpartum period can pose problems for managing weight in non-lactating women and for maintaining physical activity (Gaston \& Cramp 2013), the introduction of an exercise intervention is likely to have additional physical benefits alongside the effect of reducing symptoms of depression. Qualitative evidence suggests that additional benefits of exercise are improved confidence, body image, and mood (Pritchett et al 2017). Moreover, when lactating women are reluctant to take anti-depressant medication (Turner et al 2008) exercise provides an acceptable alternative.

Subgroup analyses revealed that exercise-based interventions targeting at-risk women with a history of depression or elevated depression symptoms postpartum yielded increased treatment effects than universal preventive interventions. A similar finding has been reported previously in the postpartum population (McCurdy et al 2017), and in young people (Carter et al 2016), thus suggesting exercise interventions may be best applied as either a targeted preventive or treatment intervention. However, when exercise could be most efficacious, it is paradoxically when an individual might be less likely to undertake exercise due to the physical symptoms of depression (i.e. fatigue, diminished concentration, disturbed sleep and appetite) understandably adversely affecting motivation and activity levels. Consequently, future studies testing exercise for postpartum women with elevated depression symptoms need to focus on how to maximise appeal of the intervention and target motivation.

Importantly, the majority of the included studies did not assess anxiety symptoms despite the well evidenced comorbidity of anxiety and depression in the post-partum period (Falah-Hassani, Shiri \& Denni 2016). Interestingly, this is not confined to exercise interventions as there is a reported general lack of research testing the efficacy/effectiveness of treatments for postnatal anxiety (Field 2018). As such, future studies should pay more attention to assessing and measuring symptoms of anxiety in pregnant and postnatal women with depression symptoms.

\section{Strengths and limitations}

This review has a number of strengths: (a) it is the first to include four RCTs of exercise for postpartum women that have not been previously included in qualitative and/or quantitative syntheses (Forsyth et al 2017; LeCheminant et al 2014; Thirruppathi et al 2014; Yang \& Chen 2017) (b) it includes only RCTs, thus recommendations are based on the best quality available evidence; (c) all subgroup analyses undertaken included a sufficient number of studies, thus reducing the likelihood of making spurious recommendations; (d) it is the first 
in this area to follow the GRADE approach for rating the quality of evidence; (e) The reporting conforms to

PRISMA guidance; and (f) the review has a prospectively registered protocol.

391

392

After careful inspection of the funnel plots, and without excluding the possibility of the publication bias, we assume that the poor methodological quality of smaller studies in this review has led to spuriously inflated effects (Sterne et al 2008). The conclusions of the review are limited by the number and quality of the included studies. Although adequate numbers of participants were included to detect a difference in SMD as was found, the small number of studies limits the subgroup analysis possible. Moreover, due to the dearth of data on anxiety symptoms no analysis was possible. In addition, the findings regarding the effects of exercise on HRQoL is limited, given that only two studies were included in the meta-analysis (Daley et al 2015; Haruna et al 2013). Finally, the overall low quality of the evidence limits the strength of the conclusions made.

400

401

\section{Quality of evidence}

402

The overall quality of evidence for exercise in depression symptoms in postpartum women is low, and our sensitivity analysis, which excluded studies at risk of selection bias, yielded a small treatment effect. Thus, the evidence does not currently support the large scale roll out of exercise interventions in treating and/or preventing depression symptoms in postpartum women.

406

\section{Conclusion}

Exercise is effective in reducing depression symptoms in postpartum women, however the effect size is small to moderate, and is based on mostly small, low quality RCTs. The sensitivity analysis produced zero heterogeneity $\left(\mathrm{I}^{2}=0 \%\right)$, and retained statistical significance, thus exercise as an intervention for postpartum depression symptom reduction certainly holds promise. Such an exercise intervention might be most effective for women with elevated symptoms of depression, and delivered with increased focus on active engagement in supervised exercise sessions.

However, there is need for high quality, sufficiently powered RCTs comparing exercise interventions against active controls. In addition, economic evaluations should be conducted in tandem with RCTs in order to assess the cost-effectiveness of exercise interventions for depression symptoms in postpartum women. 
Armstrong K, Edwards H (2003) The effects of exercise and social support on mothers reporting depressive symptoms: a pilot randomized controlled trial. International Journal of Mental Health Nursing, 12(2), 130-138.

Armstrong K., Edwards H (2004) The effectiveness of a pram-walking exercise programme in reducing depressive symptomatology for postnatal women. International Journal of Nursing Practice, 10(4), 177-194.

Austin MP, Hadzi-Pavlovic D, Priest SR, Reilly N, Wilhelm K, Saint K, Parker G (2010) Depressive and anxiety disorders in the postpartum period: how prevalent are they and can we improve their detection? Arch Womens Ment Health, 13(5), 395-401. doi:10.1007/s00737-010-0153-7.

Balshem H, Helfand M, Schunemann HJ, Oxman AD, Kunz R, Brozek J, Vist GE, Falck-Ytter Y, Meerpohl J, Norris S, et al. (2011) GRADE guidelines: 3. Rating the quality of evidence. J Clin Epidemiol. 64(4), 401-6.

Bauer A, Parsonage M, Knapp M, Lemmi V, Bayo A (2014) Costs of perinatal mental health problems. London School of Economics and Political Science, London, UK. Borenstein M, Hedges L, Higgins J, Rothstein H (2009) Introduction to meta-analysis. Chichester, UK: Wiley. Boyce P, Stubbs J, Todd A (1993) The Edinburgh Postnatal Depression Scale: validation for an Australian sample. Aust N Z J Psychiatry 27(3), 472-476. doi:10.3109/00048679309075805

Buttner MM., Brock RL, O'Hara MW, Stuart S (2015) Efficacy of yoga for depressed postpartum women: A randomized controlled trial. Complement Ther Clin Pract 21(2), 94-100. doi:10.1016/j.ctcp.2015.03.003 exercise during pregnancy with trimester-specific and postpartum quality of life and depressive symptoms in a cohort of healthy pregnant women. Arch Womens Ment Health. doi:10.1007/s00737-017-0783-0 from: http://www.crd.york.ac.uk/PROSPERO/display_record.php?ID=CRD42017068376. 

doi:10.1016/j.jaac.2016.04.016

Centre for Reviews and Dissemination (2009) Systematic reviews: CRD's guidance for undertaking reviews in health care. University of York, Centre for Reviews \& Dissemination.

447 Claesson IM, Klein S, Sydsjo G, Josefsson A (2014) Physical activity and psychological well-being in obese pregnant and postpartum women attending a weight-gain restriction programme. Midwifery, 30(1), 11-16. doi:10.1016/j.midw.2012.11.006

Cooney GM, Dwan K, Greig CA, Lawlor DA, Rimer J, Waugh FR, Mead GE (2013) Exercise for depression. Cochrane Database Syst Rev(9), CD004366. doi:10.1002/14651858.CD004366.pub6

Da Costa D, Lowensteyn I, Abrahamowicz M, Ionescu-Ittu R, Dritsa M, Rippen N et al (2009) A randomized clinical trial of exercise to alleviate postpartum depressed mood. J Psychosom Obstet Gynaecol, 30(3), 191-200. doi:10.1080/01674820903212136

Daley AJ, Blamey RV, Jolly K, Roalfe AK, Turner KM et al (2015) A pragmatic randomized controlled trial to evaluate the effectiveness of a facilitated exercise intervention as a treatment for postnatal depression: the PAMPeRS trial. Psychol Med, 45(11) 2413-2425. doi:10.1017/S0033291715000409

Daley AJ, Winter H, Grimmett C, McGuinness M, McManus R, MacArthur, C (2008) Feasibility of an exercise intervention for women with postnatal depression: a pilot randomised controlled trial. British Journal of General Practice, 58(548), 178-183. doi:10.3399/bjgp08X277195

Egger M, Smith GD, Schneider M, Minder C (1997) Bias in meta-analysis detected by a simple, graphical test. symptomatology and anxiety. Journal of Affective Disorders. 198:pp.142-147. 
Field T (2018) Postnatal anxiety prevalence, predictors and effects on development: A narrative review. Infant Behavior and Development. 51.24-32.

471 Forsyth J, Boath E, Henshaw C, Brown H (2017) Exercise as an adjunct treatment for postpartum depression for 472 women living in an inner city-A pilot study. Health Care Women Int, 38(6), 635-639. doi:10.1080/07399332.2017.1295049

Gaston A, Cramp, A (2011) Exercise during pregnancy: a review of patterns and determinants. J Sci Med Sport, 14(4) 299-305. doi:10.1016/j.jsams.2011.02.006

Grace SL, Evindar A, Stewart DE (2003) The effect of postpartum depression on child cognitive development and behavior: a review and critical analysis of the literature. Arch Womens Ment Health, 6(4) 263-274. doi:10.1007/s00737-003-0024-6

Guyatt GH, Oxman AD, Vist GE Kunz R, Falck-Ytter Y, Alonso-Coello P, Schünemann HJ (2008). GRADE: an emerging consensus on rating quality of evidence and strength of recommendations. BMJ, 336(7650), 924-926. doi:10.1136/bmj.39489.470347.AD

Haruna M, Watanabe E, Matsuzaki M, Ota E, Shiraishi M, Murayama R, Yeo S (2013) The effects of an exercise program on health-related quality of life in postpartum mothers: A randomized controlled trial. Health, $05(03)$, 432-439. doi:10.4236/health.2013.53058

Higgins JPT, Altman DG, Gøtzsche PC, Jüni P, Moher D, Oxman AD, Sterne JAC (2011) The Cochrane Collaboration's tool for assessing risk of bias in randomised trials. BMJ, 343. doi:10.1136/bmj.d5928

Higgins J, Altman D (2008) Assessing risk of bias in included studies. In J. Higgins, \& Green, S (Ed.), Cochrane handbook for systematic reviews of interventions Cochrane book series Chichester, UK: Wiley-Blackwell. doi:10.1016/j.cct.2011.01.003 

support physical activity intervention in weight management among post-partum Latinas. BMC Public Health, 14(1), 971. doi:10.1186/1471-2458-14-971

495

496

497

498

499

500

501

502

503

504

505

506

507

LeCheminant JD, Hinman T, Pratt KB, Earl N, Bailey BW, Thackeray R, Tucker LA (2014) Effect of resistance training on body composition, self-efficacy, depression, and activity in postpartum women. Scand J Med Sci Sports. 24(2):pp.414-21.

Lewis BA, Gjerdingen DK, Avery MD, Sirard JR, Guo H, Schuver K, Marcus BH (2014) A randomized trial examining a physical activity intervention for the prevention of postpartum depression: The healthy mom trial. Mental Health and Physical Activity, 7(1), 42-49. doi:10.1016/j.mhpa.2013.11.002

Matthey S (2004). Calculating clinically significant change in postnatal depression studies using the Edinburgh Postnatal Depression Scale. Journal of Affective Disorders, 78(3) 269-272. doi:10.1016/s0165-0327(02)00313-0

McCurdy AP, Boule NG, Sivak A, Davenport MH (2017). Effects of Exercise on Mild-to-Moderate Depressive Symptoms in the Postpartum Period: A Meta-analysis. Obstet Gynecol, 129(6), 1087-1097. doi:10.1097/aog.0000000000002053

Moher D, Liberati A, Tetzlaff J, Altman DG (2009) Preferred reporting items for systematic reviews and metaanalyses: the PRISMA statement. BMJ, 339. doi:10.1136/bmj.b2535

Morrell CJ, Slade P, Warner R, Paley G, Dixon S, Walters SJ, Brugha T, Barkham M, Parry G, Nicholl J (2009) Clinical effectiveness of health visitor training in psychologically informed approaches for depression in postnatal women - pragmatic cluster randomised trial in primary care. $B M J ; 338 ; \mathrm{a} 3045$

Morrell CJ, Sutcliffe P, Booth A, Stevens J, Scope A, Stevenson M, et al (2016) A systematic review, evidence synthesis and meta-analysis of quantitative and qualitative studies evaluating the clinical effectiveness, the costeffectiveness, safety and acceptability of interventions to prevent postnatal depression. Health Technol Assess ;20(37)

Morrell CJ, Warner R, Slade P, Dixon S, Walters S, Paley G, Brugha T (2009) Psychological interventions for postnatal depression: cluster randomised trial and economic evaluation. The PoNDER trial. Health Technology Assessment, 13(30), 1-153. 
518 National Institute for Health and Care Excellence (2014) Antenatal and postnatal mental health: clinical 519 management and service guidance. Clinical guideline [CG192]. Retrieved from 520 https://www.nice.org.uk/guidance/cg192

521 Norman E, Sherburn M, Osborne RH, Galea MP (2010) An exercise and education program improves well-being 522 of new mothers: a randomized controlled trial. Phys Ther, 90(3), 348-355. doi:10.2522/ptj.20090139

523 Peterson KE, Sorensen G, Pearson M, Hebert JR, Gottlieb BR, McCormick MC (2002). Design of an intervention 524 addressing multiple levels of influence on dietary and activity patterns of low-income, postpartum women. Health 525 Educ Res, 17(5), 531-540.

526 Pope CJ, Xie B, Sharma V, Campbell MK (2013) A prospective study of thoughts of self-harm and suicidal 527 ideation during the postpartum period in women with mood disorders. Arch Womens Ment Health, 16(6), 483488. doi:10.1007/s00737-013-0370-y Vizcaino, V. (2017). Effects of exercise-based interventions on postpartum depression: A meta-analysis of randomized controlled trials. Birth, 44(3) 200-208. doi:10.1111/birt.12294

532 Putnam KT, Wilcox M, Robertson-Blackmore E, Sharkey K, Bergink, V et al (2017) Clinical phenotypes of 533 perinatal depression and time of symptom onset: analysis of data from an international consortium. Lancet 534 Psychiatry. 4(6):pp.477-485.

Robichaud KP (2009) The effects of an exercise intervention on the psychological well-being of postpartum women. Dissertation Abstracts International: Section B: The Sciences and Engineering, 69(7-B), 4124.

Ryan R, Hill S (2016). How to GRADE the quality of the evidence. Cochrane Consumers and Communication Group. Retrieved from http://cccrg.cochrane.org/author-resources.

539 Saeedi S (2013) Effect of exercise program on symptoms of postpartum depression. Iranian Journal of Obstetrics, 540 Gynecology and Infertility, 15(34) 26-31.

541 Saligheh M, Hackett D, Boyce P,Cobley S (2017) Can exercise or physical activity help improve postnatal depression and weight loss? A systematic review. Arch Womens Ment Health 20(5), 595-611. 
544 Schunemann H, Oxman A, Higgins J, Vist,G, Glasziou P, Guyatt G, \& on behalf of the Cochrane Applicability 545 and Recommendations Methods Group and the Cochrane Statistical Methods Group. (2008). Presenting results 546 and 'Summary of findings' tables. In J. Higgins \& S. Green (Eds.), Cochrane handbook for systematic reviews of 547 interventions Cochrane book series. Chichester: Wiley-Blackwell.

548 Shelton S (2015) Postpartum Depressive Symptoms: A Study of Influencing Factors and an Intervention for 549 Improvement. Dissertation, Georgia State University.

550 StataCorp (2015) Stata Statistical Software: Release 14. College Station, TX: StataCorp LP.

551 Sterne J, Egger M, Moher D (2008) Chapter 10: Addressing reporting biases. In J. Higgins \& S. Green (Eds.), 552 Cochrane handbook for systematic reviews of interventions Cochrane book series Chichester, UK: Wiley553 Blackwell.

554 Surkan PJ, Gottlieb BR, McCormick MC, Hunt A, Peterson, KE (2012) Impact of a health promotion intervention 555 on maternal depressive symptoms at 15 months postpartum. Matern Child Health J, 16(1), 139-148. 556 doi:10.1007/s10995-010-0729-x

557 Teychenne M, York R (2013) Physical activity, sedentary behavior, and postnatal depressive symptoms: a review.

558 Am J Prev Med, 45(2) 217-227. doi:10.1016/j.amepre.2013.04.004

559 Thiruppathi A, Prasana B, Mastaniah E, Vamsidhar N, Himabindu P (2014) A Structured Physical Activity and 560 Health Care Education Beats Postpartum Depression for Primipara Mothers: A Pilot Randomized Controlled 561 Trail. International Journal of Physiotherapy, 1(3), 144. doi:10.15621/ijphy/2014/v1i3/53468

562 Wisner KL, Sit DK, McShea MC, Rizzo, DM et al (2013) Onset timing, thoughts of self-harm, and diagnoses in 563 postpartum women with screen-positive depression findings. JAMA Psychiatry, 70(5), 490-498. 564 doi:10.1001/jamapsychiatry.2013.87

565 Yang CL, \& Chen CH (2018) Effectiveness of aerobic gymnastic exercise on stress, fatigue, and sleep quality 566 during postpartum: A pilot randomized controlled trial. Int J Nurs Stud, 77, 1-7. 567 doi:10.1016/j.ijnurstu.2017.09.009 
Table 1: Search syntax for Medline, EMBASE and PsychINFO

\begin{tabular}{|l|l|}
\hline PICO Heading & Syntax set \\
\hline Population & $\begin{array}{l}\text { postnatal.mp. OR post-natal.mp. OR perinatal.mp. OR peri-natal.mp. OR } \\
\text { postpartum.mp. OR post-partum.mp. OR puerperium.mp. OR puerperal.mp. OR } \\
\text { pregnan\$2.mp. OR post pregnancy.mp. OR post-pregnancy.mp OR postpregnancy.mp. } \\
\text { OR motherhood.mp. OR wom\#n.mp. }\end{array}$ \\
\hline Intervention & $\begin{array}{l}\text { aerobic.mp. OR walking.ab. OR pram-walking.mp. OR exercise*.mp. OR (physical adj3 } \\
\text { activity).mp. OR (physical adj3 exercise).mp. OR (exercise adj3 intervention).mp. OR } \\
\text { exercise program\$3.mp. OR yoga.mp. OR tai-chi.mp. OR taichi.mp. OR tai chi.mp. OR } \\
\text { tai ji.mp. OR tai-ji.mp. OR (social adj3 support).mp. OR obesity.mp. OR diet.mp. OR } \\
\text { nutrition.mp. OR mindfulness.ab. OR weight loss.mp. OR physiotherapy.ab. OR physio } \\
\text { therapy.ab. OR physio-therapy.ab. OR fitness.mp. OR sport*.mp. OR muscle*.mp. OR } \\
\text { stretching.mp. OR leisure.mp. OR dance.mp. OR running.mp. }\end{array}$ \\
\hline $\begin{array}{l}\text { Depression.mp. OR Depressive.mp. OR Depressi\$2 adj3 symptom*.mp. OR (risk* adj5 } \\
\text { depress\$3).ab. OR Anxiety adj3 symptom*.mp. OR Anxiety.mp. OR Therapy adj5 } \\
\text { depression.mp. OR depression adj3 treatment.mp. OR Diagnosis adj3 depression.mp. } \\
\text { OR Prevention adj3 depression.mp. OR Stress.ab. OR Mood.ab. OR Mental health.mp. } \\
\text { OR Well-being.mp. OR Well being.mp. OR Wellbeing.mp. }\end{array}$ \\
\hline
\end{tabular}


Table 2: Summary of study characteristics

\begin{tabular}{|c|c|c|c|c|c|c|c|}
\hline Studies & Country & $\begin{array}{l}\mathbf{N} \\
(\mathrm{Ne} ; \mathrm{Nc})\end{array}$ & $\begin{array}{l}\text { Age range in } \\
\text { years, } \\
\text { (mean) }\end{array}$ & $\begin{array}{l}\text { Depression inclusion } \\
\text { criteria }\end{array}$ & $\begin{array}{l}\text { Baseline depression } \\
\text { severity }{ }^{a} \text { baseline } \\
\text { depressive symptoms } \\
\text { (mean) }\end{array}$ & Measures & $\begin{array}{l}\text { Assessment } \\
\text { time points }\end{array}$ \\
\hline $\begin{array}{l}\text { Armstrong \& } \\
\text { Edwards, } \\
2003\end{array}$ & Australia & $\begin{array}{l}\mathrm{N}=20 \\
(\mathrm{Ne}=10 \\
\mathrm{Nc}=10)\end{array}$ & $\begin{array}{l}\text { majority 21- } \\
30 \\
\text { (NR) }\end{array}$ & $\begin{array}{l}\text { Elevated depressive } \\
\text { symptoms } \\
\text { (EPDS } \geq 12 \text { ) }\end{array}$ & $\begin{array}{l}\text { Moderate } \\
\text { (half of the participants were } \\
\text { taking medication for PND); } \\
I=17.4 ; C=18.4\end{array}$ & $\begin{array}{l}\text { DASS } \\
\text { EPDS } \\
\text { GHQ12 }\end{array}$ & $\begin{array}{l}\text { Baseline, } \\
\text { Week 6, } \\
\text { Week } 12 \text { (post- } \\
\text { intervention) }\end{array}$ \\
\hline $\begin{array}{l}\text { Armstrong \& } \\
\text { Edwards, } \\
2004\end{array}$ & Australia & $\begin{array}{l}N=19 \\
(\mathrm{Ne}=9 \\
\mathrm{Nc}=10)\end{array}$ & NR & $\begin{array}{l}\text { Elevated depressive } \\
\text { symptoms } \\
\text { (EPDS } \geq 12 \text { ) }\end{array}$ & $\begin{array}{l}\text { Moderate } \\
\text { (all the participants scored } \geq 12 \\
\text { in EPDS and half of them were } \\
\text { taking medication for PND); } \\
\mathrm{I}=17.25 ; \mathrm{C}=17.17\end{array}$ & EPDS & $\begin{array}{l}\text { Baseline, } \\
\text { Week 6, } \\
\text { Week } 12 \text { (post- } \\
\text { intervention) }\end{array}$ \\
\hline $\begin{array}{l}\text { Buttner et al., } \\
2015\end{array}$ & USA & $\begin{array}{l}\mathrm{N}=57 \\
(\mathrm{Ne}=28 \\
\mathrm{Nc}=29)\end{array}$ & $\begin{array}{l}\mathrm{NR}, \\
(\mathrm{Me}=29.81 ; \\
\mathrm{Mc}=32.45)\end{array}$ & $\begin{array}{l}\text { Elevated depressive } \\
\text { symptoms } \\
\text { (HDRS } \geq 12 ; \text { PHQ-9 } \geq 10 \text { ) }\end{array}$ & $\begin{array}{l}\text { Mild to moderate } \\
(\geq 12 \text { HDRS); } \\
I=17.33 ; C=15.34\end{array}$ & $\begin{array}{l}\text { HDRS } \\
\text { IDAS } \\
\text { PHQ-9 } \\
\text { SCID-1 } \\
\text { SF-36 }\end{array}$ & $\begin{array}{l}\text { Baseline, } \\
\text { Week 2, } \\
\text { Week 4, } \\
\text { Week 6, } \\
\text { Week } 8 \text { (post- } \\
\text { intervention) }\end{array}$ \\
\hline $\begin{array}{l}\text { DaCosta et al., } \\
2009\end{array}$ & Canada & $\begin{array}{l}\mathrm{N}=88 \\
(\mathrm{Ne}=46 \\
\mathrm{Nc}=42)\end{array}$ & $\begin{array}{l}\mathrm{NR}, \\
(\mathrm{Me}=34.3 ; \\
\mathrm{Mc}=32.7)\end{array}$ & $\begin{array}{l}\text { Elevated depressive } \\
\text { symptoms } \\
\text { (EPDS } \geq 10 \text { ) }\end{array}$ & $\begin{array}{l}\text { Mild to moderate } \\
\text { ( } \geq 10 \text { EPDS); } \\
13.6 \text { for both groups }\end{array}$ & $\begin{array}{l}\text { EPDS } \\
\text { HAM-D }\end{array}$ & $\begin{array}{l}\text { Baseline, } \\
\text { Month } 3 \text { (post- } \\
\text { intervention), } \\
\text { Month } 6\end{array}$ \\
\hline $\begin{array}{l}\text { Daley et al., } \\
2015\end{array}$ & UK & $\begin{array}{l}\mathrm{N}=94 \\
(\mathrm{Ne}=47 \\
\mathrm{Nc}=47)\end{array}$ & $\begin{array}{l}N R, \\
(M e=31.7 ; \\
M c=29.3)\end{array}$ & $\begin{array}{l}\text { Elevated depressive } \\
\text { symptoms } \\
\text { (EPDS } \geq 13 \text { ) and CIS-R }\end{array}$ & $\begin{array}{l}\text { Moderate } \\
\text { ( } 39 \% \text { of participants had } \\
\text { thoughts of self-harming, } 18.1 \% \\
\text { with severe depression, } 53.2 \% \\
\text { with a moderate-severe } \\
\text { depression episode, } 15.9 \% \text { with } \\
\text { a mild depression episode, \& } \\
12.8 \% \text { with mixed anxiety and } \\
\text { depressive disorder); } \\
\text { I = } 17.3 ; C=17.5\end{array}$ & $\begin{array}{l}\text { EPDS } \\
\text { SF-12 }\end{array}$ & $\begin{array}{l}\text { Baseline, } \\
\text { Month } 6 \text { (post- } \\
\text { intervention), } \\
\text { Month } 12\end{array}$ \\
\hline
\end{tabular}




\begin{tabular}{|c|c|c|c|c|c|c|c|}
\hline $\begin{array}{l}\text { Daley et al., } \\
2008\end{array}$ & UK & $\begin{array}{l}\mathrm{N}=38 \\
(\mathrm{Ne}=20 \\
\mathrm{Nc}=18)\end{array}$ & $\begin{array}{l}\text { Majority 21- } \\
40, \\
(N R)\end{array}$ & $\begin{array}{l}\text { Clinical judgement or } \\
\text { elevated depressive } \\
\text { symptoms } \\
\text { (EPDS } \geq 12 \text { ) }\end{array}$ & $\begin{array}{l}\text { Moderate to severe } \\
\text { (most of the participants were } \\
\text { taking medication for PND); } \\
\mathrm{I}=17.7 ; \mathrm{C}=19.2\end{array}$ & EPDS & $\begin{array}{l}\text { Baseline, } \\
\text { Week } 12 \text { (post- } \\
\text { intervention) }\end{array}$ \\
\hline $\begin{array}{l}\text { Forsyth et al., } \\
2017\end{array}$ & UK & $\begin{array}{l}\mathrm{N}=22 \\
(\mathrm{Ne}=11 \\
\mathrm{Nc}=11)\end{array}$ & $\begin{array}{l}\mathrm{NR}, \\
(\mathrm{Me}=25 \\
\mathrm{Mc}=27)\end{array}$ & $\begin{array}{l}\text { Elevated depressive } \\
\text { symptoms } \\
(\text { EPDS } \geq 12 \text { ) and SCID-PN }\end{array}$ & $\begin{array}{l}\text { Moderate } \\
I=17.6 ; C=15.9\end{array}$ & $\begin{array}{l}\text { EPDS } \\
\text { SCID-PN } \\
\text { diagnosis }\end{array}$ & $\begin{array}{l}\text { Baseline, } \\
\text { Week } 12 \text { (post- } \\
\text { intervention), } \\
\text { Month } 6\end{array}$ \\
\hline $\begin{array}{l}\text { Haruna et al., } \\
2013\end{array}$ & Japan & $\begin{array}{l}\mathrm{N}=101 \\
(\mathrm{Ne}=50 \\
\mathrm{Nc}=51)\end{array}$ & $\begin{array}{l}\mathrm{NR}, \\
(\mathrm{Me}=33.8 \\
\mathrm{Mc}=33.7)\end{array}$ & N/A & $\begin{array}{l}\text { None } \\
I=4.1 ; C=5.9\end{array}$ & $\begin{array}{l}\text { EPDS } \\
\text { SF-36v2 }\end{array}$ & $\begin{array}{l}\text { Baseline, } \\
\text { Month } 2 \text { (post- } \\
\text { intervention) }\end{array}$ \\
\hline $\begin{array}{l}\text { Keller et al., } \\
2014\end{array}$ & USA & $\begin{array}{l}\mathrm{N}=139 \\
(\mathrm{Ne}=71 \\
\mathrm{Nc}=68)\end{array}$ & $\begin{array}{l}\text { NR, } \\
(M=28.3)\end{array}$ & $\mathrm{N} / \mathrm{A}$ & $\begin{array}{l}\text { Mild } \\
\mathrm{I}=8.21 ; \mathrm{C}=8.69\end{array}$ & EPDS & $\begin{array}{l}\text { Baseline, } \\
\text { Month } 6 \text { (post- } \\
\text { intervention), } \\
\text { Month } 12\end{array}$ \\
\hline $\begin{array}{l}\text { LeCheminant } \\
\text { et al., } \\
2014\end{array}$ & USA & $\begin{array}{l}\mathrm{N}=60 \\
(\mathrm{Ne}=30 \\
\mathrm{Nc}=30)\end{array}$ & $\begin{array}{l}\mathrm{NR}, \\
(\mathrm{Me}=26.9 \\
\mathrm{Mc}=25.9)\end{array}$ & $\mathrm{N} / \mathrm{A}$ & $\begin{array}{l}\text { None } \\
I=9.5 ; C=N R\end{array}$ & CES-D & $\begin{array}{l}\text { Baseline, } \\
\text { Month 2, } \\
\text { Month } 4 \text { (post- } \\
\text { intervention) }\end{array}$ \\
\hline $\begin{array}{l}\text { Lewis et al., } \\
2014\end{array}$ & USA & $\begin{array}{l}\mathrm{N}=130 \\
(\mathrm{Ne}=66 \\
\mathrm{Nc}=64)\end{array}$ & $\begin{array}{l}\text { NR, } \\
(\mathrm{Me}=31.69 ; \\
\mathrm{Mc}=31.39)\end{array}$ & $\begin{array}{l}\text { Personal history of } \\
\text { depression or maternal } \\
\text { history of depression } \\
\text { but individuals with } \\
\text { current depressive } \\
\text { episodes were excluded }\end{array}$ & $\begin{array}{l}\text { Mild } \\
\text { ( } 29 \% \text { were taking antidepressant } \\
\text { medication); } \\
\mathrm{I}=5.0 ; C=5.0\end{array}$ & $\begin{array}{l}\text { EPDS } \\
\text { PHQ-9 } \\
\text { SCID-I }\end{array}$ & $\begin{array}{l}\text { Baseline, } \\
\text { Month } 6 \text { (post- } \\
\text { intervention) }\end{array}$ \\
\hline $\begin{array}{l}\text { Norman et al., } \\
2010\end{array}$ & Australia & $\begin{array}{l}\mathrm{N}=161 \\
(\mathrm{Ne}=80 \\
\mathrm{Nc}=81)\end{array}$ & $\begin{array}{l}17-41 \\
(\mathrm{Me}=29.3 \\
\mathrm{Mc}=30.1)\end{array}$ & N/A & $\begin{array}{l}\text { Mild } \\
I=8.0 ; C=6.75\end{array}$ & EPDS & $\begin{array}{l}\text { Baseline, } \\
\text { Week } 8 \text { (post- } \\
\text { intervention), } \\
\text { Week } 12\end{array}$ \\
\hline $\begin{array}{l}\text { Robichaud, } \\
2009 \\
\text { (unpublished } \\
\text { thesis) }\end{array}$ & USA & $\begin{array}{l}\mathrm{N}=48 \\
(\mathrm{Ne}=25 \\
\mathrm{Nc}=23)\end{array}$ & $\begin{array}{l}20-40 \\
(\mathrm{Me}=31.1 \\
\mathrm{Mc}=30.4)\end{array}$ & $\mathrm{N} / \mathrm{A}$ & $\begin{array}{l}\text { Moderate to severe } \\
I=19.76 ; C=18.87\end{array}$ & EPDS & $\begin{array}{l}\text { Baseline, } \\
\text { Week } 6 \text { (post- } \\
\text { intervention) }\end{array}$ \\
\hline
\end{tabular}




\begin{tabular}{|c|c|c|c|c|c|c|c|}
\hline $\begin{array}{l}\text { Saeedi et al., } \\
2013\end{array}$ & Iran & $\begin{array}{l}\mathrm{N}=40 \\
(\mathrm{Ne}=20 \\
\mathrm{Nc}=20)\end{array}$ & $\begin{array}{l}\text { NR, } \\
\text { (Me 28.48; } \\
\text { Mc 27.76) }\end{array}$ & $\begin{array}{l}\text { Elevated depressive } \\
\text { symptoms } \\
(\text { EPDS } \geq 12 \text { ) }\end{array}$ & $\begin{array}{l}\text { Moderate to severe } \\
I=19.14 ; C=18.22\end{array}$ & EPDS & $\begin{array}{l}\text { Baseline, Week } \\
12 \text { (post- } \\
\text { intervention) }\end{array}$ \\
\hline $\begin{array}{l}\text { Shelton, } \\
2015 \\
\text { (unpublished } \\
\text { thesis) }\end{array}$ & USA & $\begin{array}{l}\mathrm{N}=6 \\
(\mathrm{Ne}=3 \\
\mathrm{Nc}=3)\end{array}$ & $\begin{array}{l}\text { NR, } \\
(\mathrm{Me}=26.7 \\
\mathrm{Mc}=25))\end{array}$ & $\begin{array}{l}\text { Elevated depressive } \\
\text { symptoms } \\
\text { (EPDS } \geq 7 \text { ) }\end{array}$ & $\begin{array}{l}\text { Mild } \\
I=7.67 ; C=9.33\end{array}$ & EPDS & $\begin{array}{l}\text { Baseline } \\
\text { Week } 6 \text { (post- } \\
\text { intervention) }\end{array}$ \\
\hline $\begin{array}{l}\text { Surkan et al., } \\
2012\end{array}$ & USA & $\begin{array}{l}\mathrm{N}=679 \\
(\mathrm{Ne}= \\
337 \\
\mathrm{Nc}=342)\end{array}$ & $\begin{array}{l}18-44 \\
(\mathrm{Me}=26.7 \\
\mathrm{Mc}=26.3)\end{array}$ & $\mathrm{N} / \mathrm{A}$ & $\begin{array}{l}\text { Moderate } \\
I=14.3 ; C=14.0\end{array}$ & CES-D & $\begin{array}{l}\text { Baseline, } \\
\text { Month } 14 \text { (post- } \\
\text { intervention) }\end{array}$ \\
\hline $\begin{array}{l}\text { Thiruppathi et } \\
\text { al., } \\
2014\end{array}$ & India & $\begin{array}{l}\mathrm{N}=45 \\
(\mathrm{Ne}=22 \\
\mathrm{Nc}=23)\end{array}$ & $\begin{array}{l}\mathrm{NR}, \\
(\mathrm{Me}=26.3 \\
\mathrm{Mc}=25.1)\end{array}$ & N/A & $\begin{array}{l}\text { Mild } \\
I=7.95 ; C=7.76\end{array}$ & EPDS & $\begin{array}{l}\text { Baseline, } \\
\text { Week } 4 \text { (post- } \\
\text { intervention) }\end{array}$ \\
\hline $\begin{array}{l}\text { Yang \& Chen, } \\
2017\end{array}$ & Taiwan & $\begin{array}{l}\mathrm{N}=140 \\
(\mathrm{Ne}=70 \\
\mathrm{Nc}=70)\end{array}$ & $\begin{array}{l}\text { NR, } \\
(\mathrm{Me}=31.89 \\
\mathrm{Mc}=32.45)\end{array}$ & N/A & $\begin{array}{l}\text { Mild } \\
I=9.11 ; C=8.45\end{array}$ & EPDS & $\begin{array}{l}\text { Baseline, } \\
\text { Week 4, Week } 12 \\
\text { (post- } \\
\text { intervention) }\end{array}$ \\
\hline
\end{tabular}

Note. CES-D = Centre for Epidemiologic Studies Depression Scale; DASS = Depression Anxiety Stress Scale; EPDS = Edinburgh Postnatal Depression Scale; GHQ12 = ; HAM$\mathrm{D} / \mathrm{HDRS}=$ Hamilton Depression Rating Scale; IDAS = Inventory of Depression and Anxiety Symptoms; $\mathrm{M}=$ mean age; $\mathrm{Mc}=\mathrm{Mean}$ age of control group; Me = Mean age of experimental group; $\mathrm{N}=$ Sample size, $\mathrm{N} / \mathrm{A}=$ Not Applicable; Nc = Numbers in control group; Ne $=$ Numbers in experimental group; NR = Not Reported; PHQ-9 = Patient Health Questionnaire; RCT = Randomised Controlled Trial; SCID-I = Structured Clinical Interview for DSM-IV Axis I Disorders; SCID-PN = Structured Clinical Interview for DSM-IV (Perinatal Version); SF-12 = 12-Item Short-Form Health Survey ; SF-36 = Medical Outcomes Study 36-Item Short-Form Health Survey

a Assessments were based on Cox et al. (1987), Kroenke et al. (2001), Radloff (1977), Zimmerman et al. (2013), and McCabe-Beane, Segre, Perkhounkova, Stuart, \& O'Hara, 2016. 
Table 3. Characteristics of exercise and physical activity interventions

\begin{tabular}{|c|c|c|c|c|c|c|c|c|}
\hline Studies & $\begin{array}{l}\text { Type of } \\
\text { intervention }\end{array}$ & Provider & $\begin{array}{l}\text { Exercise } \\
\text { type }\end{array}$ & $\begin{array}{l}\text { Intervention } \\
\text { duration } \\
\text { (weeks or } \\
\text { months) }\end{array}$ & $\begin{array}{l}\text { Session duration } \\
\text { (mins.); intensity }\end{array}$ & $\begin{array}{l}\text { Session } \\
\text { frequency per } \\
\text { week }\end{array}$ & $\begin{array}{l}\text { Intervention } \\
\text { arm content } \\
\text { and format } \\
\text { (individual or } \\
\text { group based) }\end{array}$ & $\begin{array}{l}\text { Control arm } \\
\text { content }\end{array}$ \\
\hline $\begin{array}{l}\text { Armstrong \& } \\
\text { Edwards, } \\
2003\end{array}$ & $\begin{array}{l}\text { Targeted } \\
\text { (indicated) }\end{array}$ & $\begin{array}{l}\text { Supervised; } \\
\text { NQ }\end{array}$ & Aerobic & 12 weeks & $\begin{array}{l}30-40 ; \\
\text { moderate intensity }\end{array}$ & $\begin{array}{l}3 X \text { exercise } \\
1 X \text { social } \\
\text { support }\end{array}$ & $\begin{array}{l}\text { Pram-walking and } \\
\text { informal social } \\
\text { support session } \\
\text { Group-based }\end{array}$ & \begin{tabular}{|l|}
$\mathrm{NI}$ \\
(circular walking \\
test at baseline \\
and post- \\
intervention, \\
plus an interim \\
phone support \\
session) \\
\end{tabular} \\
\hline $\begin{array}{l}\text { Armstrong \& } \\
\text { Edwards, } \\
2004\end{array}$ & $\begin{array}{l}\text { Targeted } \\
\text { (indicated) }\end{array}$ & $\begin{array}{l}\text { Supervised and } \\
\text { Non-supervised; } \\
\text { NQ }\end{array}$ & Aerobic & 12 weeks & $\begin{array}{l}40 ; \\
\text { moderate intensity }\end{array}$ & $\begin{array}{l}2 \mathrm{X} \text { supervised } \\
\text { exercise } \\
1 \mathrm{X} \text { unsupervised } \\
\text { exercise }\end{array}$ & $\begin{array}{l}\text { Pram-walking } \\
\text { Group-based }\end{array}$ & \begin{tabular}{|l|} 
AC \\
(non-structured, \\
social support \\
sessions (once \\
per week) \\
\end{tabular} \\
\hline $\begin{array}{l}\text { Buttner et } \\
\text { al., } \\
2015\end{array}$ & $\begin{array}{l}\text { Targeted } \\
\text { (indicated) }\end{array}$ & $\begin{array}{l}\text { Supervised and } \\
\text { non-supervised; } \\
\text { Q }\end{array}$ & Yoga & 8 weeks & $\begin{array}{l}60 \text { for supervised } \\
\text { and } 30 \text { for } \\
\text { unsupervised; } \\
\text { NR }\end{array}$ & $\begin{array}{l}2 \mathrm{X} \text { supervised } \\
\text { yoga } \\
1 \mathrm{X} \text { unsupervised } \\
\text { yoga (the } \\
\text { minimum) }\end{array}$ & $\begin{array}{l}\text { Sun salutations, } \\
\text { balancing, } \\
\text { twisting, and } \\
\text { relaxation poses } \\
\text { Individual and } \\
\text { group-based }\end{array}$ & WLC \\
\hline $\begin{array}{l}\text { DaCosta et } \\
\text { al., } \\
2009\end{array}$ & $\begin{array}{l}\text { Targeted } \\
\text { (indicated) }\end{array}$ & $\begin{array}{l}\text { Supervised and } \\
\text { non-supervised; } \\
\text { Q }\end{array}$ & $\begin{array}{l}\text { Aerobic } \\
\text { exercise, plus } \\
\text { coaching }\end{array}$ & 12 weeks & $\begin{array}{l}90 \text { for the first } \\
\text { supervised and } 30 \\
\text { for the three follow- } \\
\text { up coaching } \\
\text { sessions, } \\
60-120 / \text { week } \\
\text { unsupervised; } \\
\text { moderate to high } \\
\text { intensity }\end{array}$ & $\begin{array}{l}4 \mathrm{X} \text { supervised } \\
\text { (within } 12 \\
\text { weeks) } \\
\text { Plus, individual } \\
\text { weekly sessions }\end{array}$ & $\begin{array}{l}\text { Stretching, } \\
\text { strength, and/or } \\
\text { cardiovascular } \\
\text { exercises, plus } \\
\text { information and } \\
\text { support elements } \\
\text { Individual-based }\end{array}$ & UC \\
\hline
\end{tabular}




\begin{tabular}{|c|c|c|c|c|c|c|c|c|}
\hline $\begin{array}{l}\text { Daley et al., } \\
2015\end{array}$ & Treatment & $\begin{array}{l}\text { Non-supervised; } \\
\text { N/A }\end{array}$ & $\begin{array}{l}\text { Coaching } \\
\text { (face-to-face } \\
\text { exercise } \\
\text { consultations } \\
\text { \& supportive } \\
\text { telephone } \\
\text { calls) }\end{array}$ & 6 months & $\begin{array}{l}40-60 \text { for the } \\
\text { personalised } \\
\text { consultations } \\
15-20 \text { for the } \\
\text { telephone calls }\end{array}$ & $\begin{array}{l}2 \mathrm{X} \text { personalised } \\
\text { exercise } \\
\text { consultations } \\
\text { (months } 1 \& 2 \text { ) } \\
\text { and } \\
\text { telephone calls } \\
\text { (months } 3 \& 4 \text { ) }\end{array}$ & $\begin{array}{l}\text { Promotion of } \\
\text { physical exercise } \\
\text { of moderate } \\
\text { intensity on a 3-5 } \\
\text { days per week } \\
\text { basis } \\
\text { Individual-based }\end{array}$ & UC \\
\hline $\begin{array}{l}\text { Daley et al., } \\
2008\end{array}$ & $\begin{array}{l}\text { Targeted } \\
\text { (indicated) }\end{array}$ & $\begin{array}{l}\text { Non-supervised; } \\
\text { N/A }\end{array}$ & Coaching & 12 weeks & $\begin{array}{l}60 \text { for the } \\
\text { personalised } \\
\text { consultations } \\
10 \text { for the telephone } \\
\text { calls }\end{array}$ & $\begin{array}{l}2 \times \text { personalised } \\
\text { exercise } \\
\text { consultations } \\
\text { over } 12 \text { weeks } \\
\text { and } 2 \times \text { follow- } \\
\text { up support } \\
\text { phone calls at } \\
\text { weeks } 3 \text { and } 9 \text {, }\end{array}$ & $\begin{array}{l}\text { Enhancing } \\
\text { motivation and } \\
\text { self-efficacy for } \\
\text { undertaking } \\
\text { moderate } \\
\text { exercise on a } \\
\text { weekly basis, and } \\
\text { preventing } \\
\text { relapse } \\
\text { Individual-based }\end{array}$ & UC \\
\hline $\begin{array}{l}\text { Forsyth et } \\
\text { al., } \\
2017\end{array}$ & Treatment & $\begin{array}{l}\text { Supervised and } \\
\text { non-supervised; } \\
\text { NR }\end{array}$ & $\begin{array}{l}\text { Coaching and } \\
\text { aerobic } \\
\text { exercise }\end{array}$ & 12 weeks & $\begin{array}{l}60 \text { for the } \\
\text { personalised } \\
\text { consultation } \\
\text { And/or } \\
150 \text { of group-based } \\
\text { or self-initiated } \\
\text { exercise at } \\
\text { moderate intensity } \\
\text { (60 for each group- } \\
\text { based session) }\end{array}$ & $\begin{array}{l}1 \mathrm{X} \text { personalised } \\
\text { motivational } \\
\text { consultation in } \\
12 \text { weeks } \\
\text { (number of } \\
\text { group-based } \\
\text { and/or } \\
\text { individual } \\
\text { sessions per } \\
\text { week is not } \\
\text { reported) }\end{array}$ & $\begin{array}{l}\text { Motivational and } \\
\text { behaviour change } \\
\text { coaching and } \\
\text { pram walking or } \\
\text { facility based } \\
\text { exercise } \\
\text { Individual and } \\
\text { group-based }\end{array}$ & UC \\
\hline $\begin{array}{l}\text { Haruna et } \\
\text { al., } \\
2013\end{array}$ & Universal & $\begin{array}{l}\text { Supervised; } \\
\text { Q }\end{array}$ & Aerobic & 2 months & 90 & $\begin{array}{l}4 \mathrm{X} \text { supervised } \\
\text { exercise }\end{array}$ & $\begin{array}{l}\text { Aerobic and } \\
\text { muscular } \\
\text { stretching } \\
\text { Group-based }\end{array}$ & $\mathrm{NI}$ \\
\hline
\end{tabular}




\begin{tabular}{|c|c|c|c|c|c|c|c|c|}
\hline $\begin{array}{l}\text { Keller et al., } \\
2014\end{array}$ & Universal & $\begin{array}{l}\text { Supervised; } \\
\mathrm{NQ}\end{array}$ & $\begin{array}{l}\text { Coaching } \\
\text { (social } \\
\text { support) plus } \\
\text { group walking }\end{array}$ & 12 weeks & $\begin{array}{l}\text { NR; } \\
\text { moderate intensity }\end{array}$ & $1 \mathrm{X}$ supervised & $\begin{array}{l}\text { Emotional, } \\
\text { instrumental, } \\
\text { appraisal, and } \\
\text { informational } \\
\text { support plus } \\
\text { group walking } \\
\text { Group-based }\end{array}$ & $\begin{array}{l}\text { AC } \\
\text { (weekly } \\
\text { telephone, } \\
\text { informative } \\
\text { sessions) }\end{array}$ \\
\hline $\begin{array}{l}\text { LeCheminant } \\
\text { et al., } \\
2014\end{array}$ & Universal & $\begin{array}{l}\text { Supervised and } \\
\text { non-supervised; } \\
\text { Q }\end{array}$ & $\begin{array}{l}\text { Resistance } \\
\text { training for } \\
\text { major muscle } \\
\text { groups }\end{array}$ & $\begin{array}{l}18 \text { weeks (4 } \\
\text { months) }\end{array}$ & $\begin{array}{l}\mathrm{NR} ; \\
\text { mild to moderate } \\
\text { intensity }\end{array}$ & $\begin{array}{l}2 \mathrm{X} \text { supervised } \\
\text { and } \\
\text { unsupervised }\end{array}$ & $\begin{array}{l}\text { Leg extension, } \\
\text { seated leg curl, } \\
\text { leg press, biceps } \\
\text { curl, shoulder } \\
\text { press, chestpress, } \\
\text { seated row, and } \\
\text { abdominal curl- } \\
\text { ups } \\
\text { Individual-based }\end{array}$ & $\begin{array}{l}\text { AC } \\
\text { (flexibility } \\
\text { training) }\end{array}$ \\
\hline $\begin{array}{l}\text { Lewis et al., } \\
2014\end{array}$ & $\begin{array}{l}\text { Targeted } \\
\text { (selective) }\end{array}$ & $\begin{array}{l}\text { Unsupervised; } \\
\text { N/A }\end{array}$ & Coaching & 6 months & $\begin{array}{l}\text { NR; } \\
\text { progressive } \\
\text { intensity }\end{array}$ & $\begin{array}{l}1 X \text { telephone } \\
\text { coaching (month } \\
1 \text { ) } \\
2 X \text { telephone } \\
\text { coaching per } \\
\text { month (months } \\
2 \& 3 \text { ) } \\
\text { And } \\
1 X \text { telephone } \\
\text { coaching per } \\
\text { month (months } \\
4,5, \& 6 \text { ) } \\
\end{array}$ & $\begin{array}{l}\text { Motivational } \\
\text { strategies based } \\
\text { on SCT and TTM } \\
\text { Individual-based }\end{array}$ & $\begin{array}{l}\text { AC } \\
\text { wellness/support } \\
\text { contact (11 } \\
\text { phone-coaching } \\
\text { sessions over } 6 \\
\text { months) }\end{array}$ \\
\hline $\begin{array}{l}\text { Norman et } \\
\text { al., } \\
2010\end{array}$ & Universal & $\begin{array}{l}\text { Supervised; } \\
\text { Q }\end{array}$ & $\begin{array}{l}\text { Aerobic, } \\
\text { strengthening, } \\
\text { and coaching }\end{array}$ & 8 weeks & $\begin{array}{l}60 \text { mins. of } \\
\text { supervised exercise } \\
\text { sessions } \\
\text { and } \\
30 \text { mins. of coaching } \\
\text { session }\end{array}$ & $\begin{array}{l}1 \mathrm{X} \text { supervised } \\
\text { exercise } \\
1 \mathrm{X} \text { coaching }\end{array}$ & $\begin{array}{l}\text { Cardiovascular } \\
\text { and strength } \\
\text { components } \\
\text { Group-based }\end{array}$ & $\begin{array}{l}\text { UC } \\
\text { (education-only } \\
\text { group) }\end{array}$ \\
\hline
\end{tabular}




\begin{tabular}{|c|c|c|c|c|c|c|c|c|}
\hline $\begin{array}{l}\text { Robichaud, } \\
2009\end{array}$ & $\begin{array}{l}\text { Targeted } \\
\text { (indicated) }\end{array}$ & $\begin{array}{l}\text { Unsupervised; } \\
\text { N/A }\end{array}$ & Aerobic & 6 weeks & $\begin{array}{l}30 \text { mins. walking, } \\
45-60 \text { mins } \\
\text { supervised initial } \\
\text { session; } \\
\text { NR }\end{array}$ & $3 \mathrm{X}$ unsupervised & $\begin{array}{l}\text { Video/DVD-based } \\
\text { exercise (walking) } \\
\text { Individual-based }\end{array}$ & $\mathrm{NI}$ \\
\hline $\begin{array}{l}\text { Saeedi et al., } \\
2013\end{array}$ & $\begin{array}{l}\text { Targeted } \\
\text { (indicated) }\end{array}$ & $\begin{array}{l}\text { Supervised; } \\
\mathrm{NQ}\end{array}$ & Aerobic & 12 weeks & $\begin{array}{l}45 ; \\
N R\end{array}$ & $3 \times$ supervised & $\begin{array}{l}\text { Aerobic \& } \\
\text { stretching } \\
\text { Group-based }\end{array}$ & NR \\
\hline $\begin{array}{l}\text { Shelton et } \\
\text { al., } \\
2015\end{array}$ & Universal & $\begin{array}{l}\text { Unsupervised; } \\
\text { N/A }\end{array}$ & Aerobic & 6 weeks & $\begin{array}{l}\text { 30; moderate } \\
\text { intensity }\end{array}$ & $3 \mathrm{X}$ unsupervised & $\begin{array}{l}\text { stroller-walking } \\
\text { intervention at } \\
\text { plus receiving } \\
\text { education } \\
\text { materials } \\
\text { Individual-based }\end{array}$ & $\begin{array}{l}\mathrm{NI} \\
\text { (receiving the } \\
\text { education } \\
\text { material only) }\end{array}$ \\
\hline $\begin{array}{l}\text { Surkan et al., } \\
2012\end{array}$ & Universal & $\begin{array}{l}\text { Unsupervised; } \\
\text { N/A }\end{array}$ & $\begin{array}{l}\text { Health } \\
\text { promotion } \\
\text { and coaching } \\
\text { (home visits } \\
\text { and telephone } \\
\text { calls) }\end{array}$ & 12 months & $\begin{array}{l}\text { NR; } \\
\text { N/A }\end{array}$ & $\begin{array}{l}5 \mathrm{X} \text { home visits } \\
\text { (within } 12 \\
\text { months) and } \\
1 \mathrm{X} \text { phone call } \\
\text { per month }\end{array}$ & $\begin{array}{l}\text { Educational } \\
\text { training, } \\
\text { motivational } \\
\text { interviewing, and } \\
\text { coaching includes } \\
\text { objectives to } \\
\text { perform } \\
30 \text { min of physical } \\
\text { activity per day, } \\
\text { at least } 5 \text { days per } \\
\text { week } \\
\text { Individual-based }\end{array}$ & $\begin{array}{l}\text { UC } \\
\text { (education } \\
\text { training only) }\end{array}$ \\
\hline $\begin{array}{l}\text { Thiruppathi } \\
\text { et al., } \\
2014\end{array}$ & Universal & $\begin{array}{l}\text { Supervised; } \\
\text { Q }\end{array}$ & $\begin{array}{l}\text { Aerobic, } \\
\text { education \& } \\
\text { coaching }\end{array}$ & 4 weeks & $\begin{array}{l}45 ; \\
N R\end{array}$ & $\begin{array}{l}1 \mathrm{X} \text { supervised } \\
\text { exercise }\end{array}$ & $\begin{array}{l}\text { warm-up, } \\
\text { cardiovascular } \\
\text { intervals, body } \\
\text { toning, core } \\
\text { pelvic floor } \\
\text { exercises, } \\
\text { followed by cool } \\
\end{array}$ & UC \\
\hline
\end{tabular}




\begin{tabular}{|c|c|c|c|c|c|c|c|c|}
\hline & & & & & & & $\begin{array}{l}\text { down with } \\
\text { stretching } \\
\text { Individual-based }\end{array}$ & \\
\hline $\begin{array}{l}\text { Yang \& } \\
\text { Chen, } \\
2017\end{array}$ & Universal & $\begin{array}{l}\text { Unsupervised; } \\
\text { N/A }\end{array}$ & $\begin{array}{l}\text { DVD-based, } \\
\text { Yoga, aerobic }\end{array}$ & 3 months & $\begin{array}{l}\text { 15; } \\
\text { progressive } \\
\text { intensity }\end{array}$ & $3 \mathrm{X}$ unsupervised & $\begin{array}{l}\text { Aerobic, muscle } \\
\text { stretching and } \\
\text { strengthening } \\
\text { Individual-based }\end{array}$ & UC \\
\hline
\end{tabular}

Note. $\mathrm{N} / \mathrm{A}=$ Not applicable; $\mathrm{NI}$ = Non-intervention; NQ = Not qualified; NR = Not reported; Q = Qualified; SCT = Social Cognitive Theory; TTM = Transtheoretical Model of exercise; UC = Usual care 
Table 4. GRADE table for assessing the quality of evidence

\begin{tabular}{|c|c|c|c|c|c|c|c|c|c|c|c|c|}
\hline \multicolumn{7}{|c|}{ Certainty Assessment } & \multicolumn{5}{|c|}{ Summary of findings } & \multirow[b]{2}{*}{ Importance** } \\
\hline $\begin{array}{l}\text { No of } \\
\text { studies }\end{array}$ & $\begin{array}{l}\text { Study } \\
\text { design }\end{array}$ & $\begin{array}{l}\text { Risk of } \\
\text { bias }\end{array}$ & Inconsistency & Indirectness & Imprecision & $\begin{array}{l}\text { Other } \\
\text { considerations }\end{array}$ & \multicolumn{2}{|c|}{ No of pts. } & \multicolumn{2}{|c|}{ Effect } & Certainty & \\
\hline \multicolumn{13}{|c|}{$\begin{array}{l}\text { Outcome: Depressive symptoms in postpartum women in } 4 \text { to } 52 \text { weeks } \\
\text { Comparison: Exercise-based and physical activity interventions versus all ty } \\
\text { postpartum women receiving the allocated intervention within } 4 \text { and } 52\end{array}$} \\
\hline 17 & RCT & Serious & Not serious & Not serious & Serious & None & 703 & 725 & $\begin{array}{l}-0.64 \\
(-0.96,- \\
0.33)^{\wedge}\end{array}$ & $\begin{array}{l}-1.92 \\
(-2.88,- \\
0.99)\end{array}$ & LOW & $\begin{array}{l}\text { Non-clinically } \\
\text { significant }\end{array}$ \\
\hline
\end{tabular}

* SMD have been re-expressed in MD using a familiar instrument (EPDS) in order to facilitate clinical interpretation (Ryan \& Hill, 2016; Schunemann et al, 2008). A standard deviation for EPDS scores has been used from a large UK sample of women (Morrell et al, 2009) ** Clinical significance in EPDS change scores was based on Matthey $\wedge I^{2}=86 \%$ for this effect estimate 


\section{Figure 1: PRISMA Flow diagram}

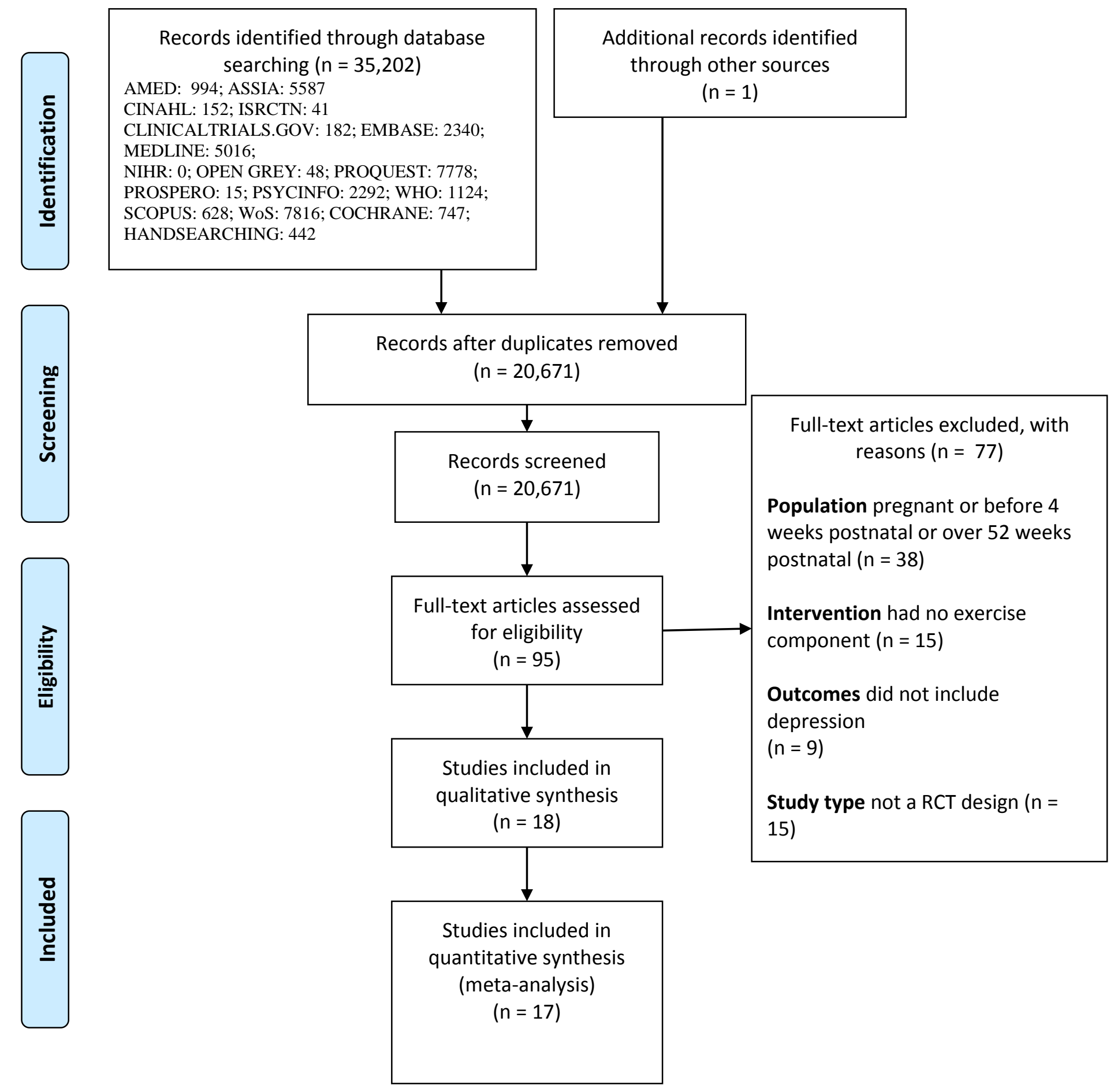

From: Moher D, Liberati A, Tetzlaff J, Altman DG, The PRISMA Group (2009). Preferred Reporting /tems for Systematic Reviews and MetaAnalyses: The PRISMA Statement. PLoS Med 6(7): e1000097. doi:10.1371/journal.pmed1000097 
Figure 2 Risk of bias assessment for each induded study

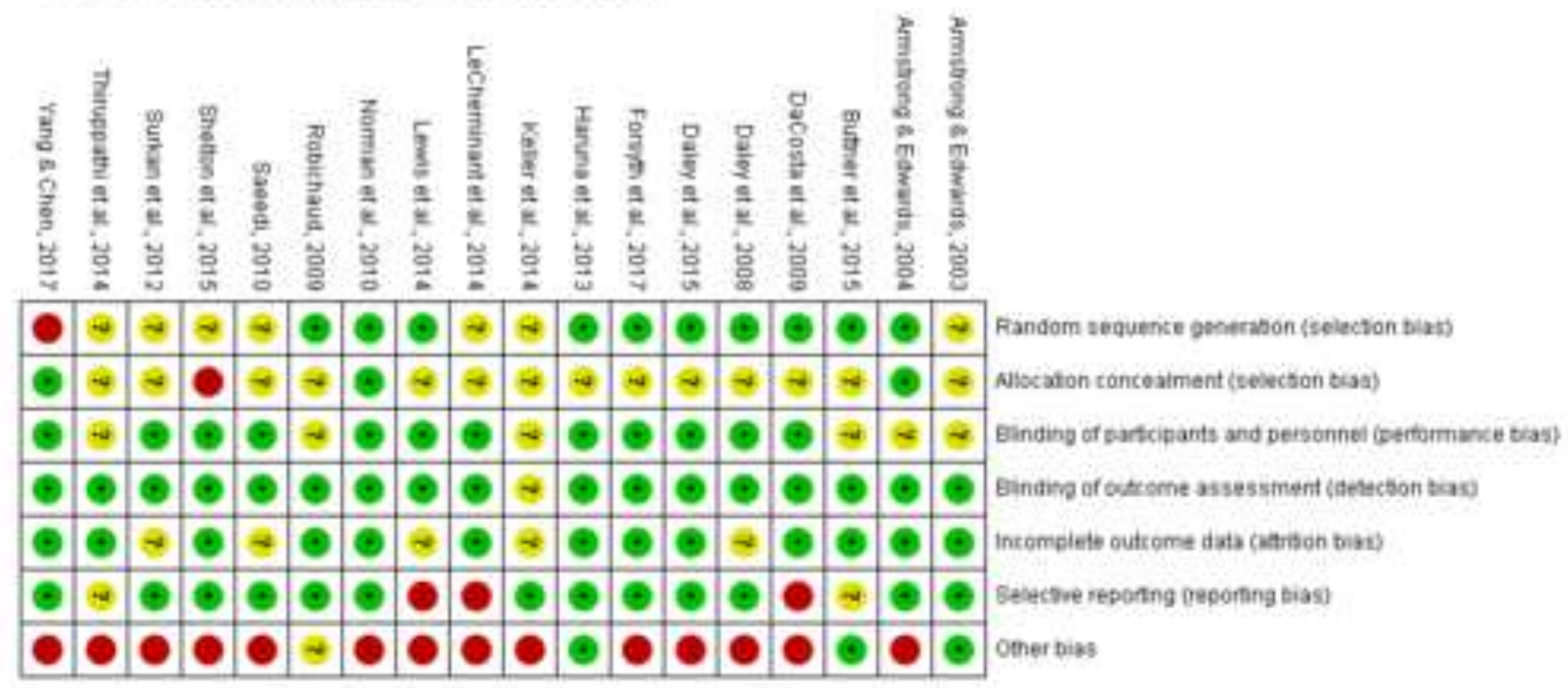


Figure 3: Forest plot and effect size estimates for the effectiveness of exercise-based and physical activity interventions in reducing depressive symptoms

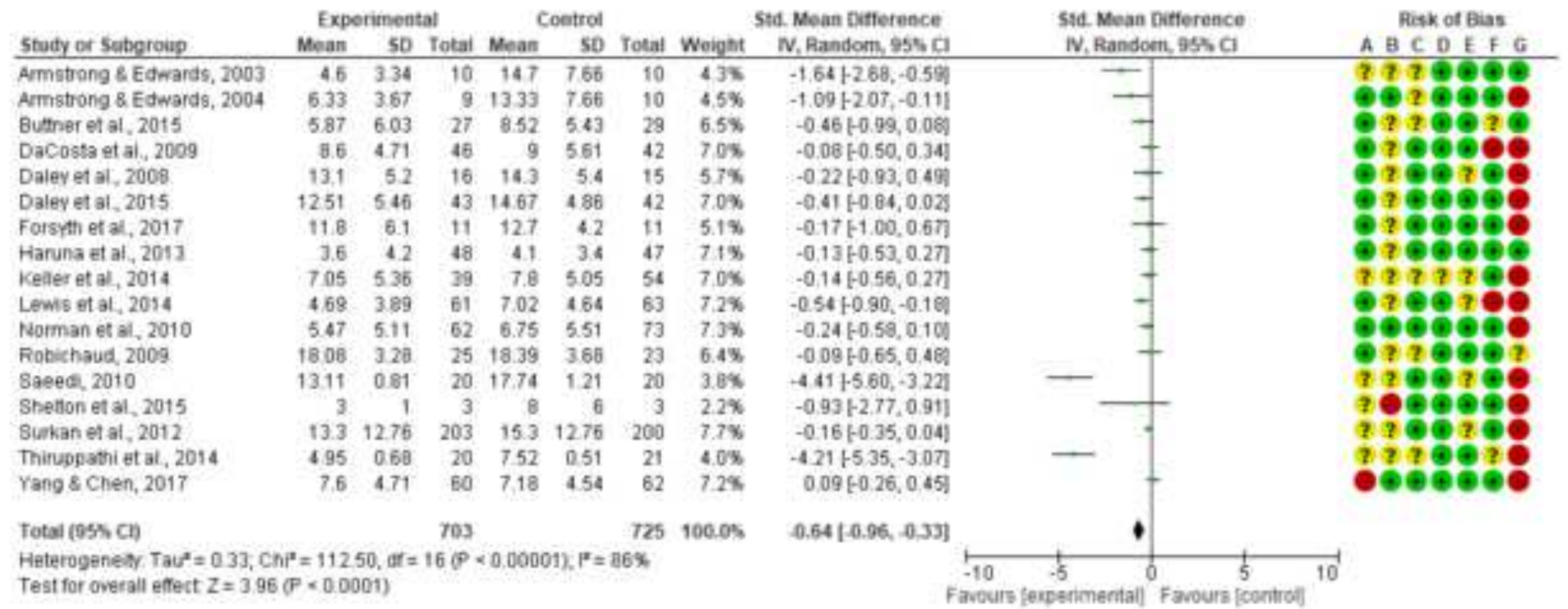

Amstrong \& Edwards, 2003

$-1.64+2.68,-0.59$

$0.205,-0.11$

$-0.08+-0.50,0.34$

5. $6 \quad 471$

Dalev et al, 2008

vet i, 2015

celer et al, 2014

Robichaud 2009

Thirupesthi et at, 2014

$251 \quad 5.46$

$43 \quad 1467 \quad 486$

$3.6 \%$

$\begin{array}{lllllll}13.3 & 12.76 & 203 & 15.3 & 1276 & 200 & 7.7 \%\end{array}$

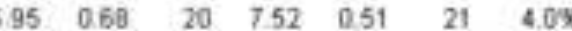

Total (ges, $\mathrm{Cr}$

tos

725100.05

Test for overall effect $Z=3,96(F \times 0.0001)$

Favours [experimental] Favours [controlf 
Figure 4: Senaitivity analysis of studies rated as low risk of bias for random sequence generation

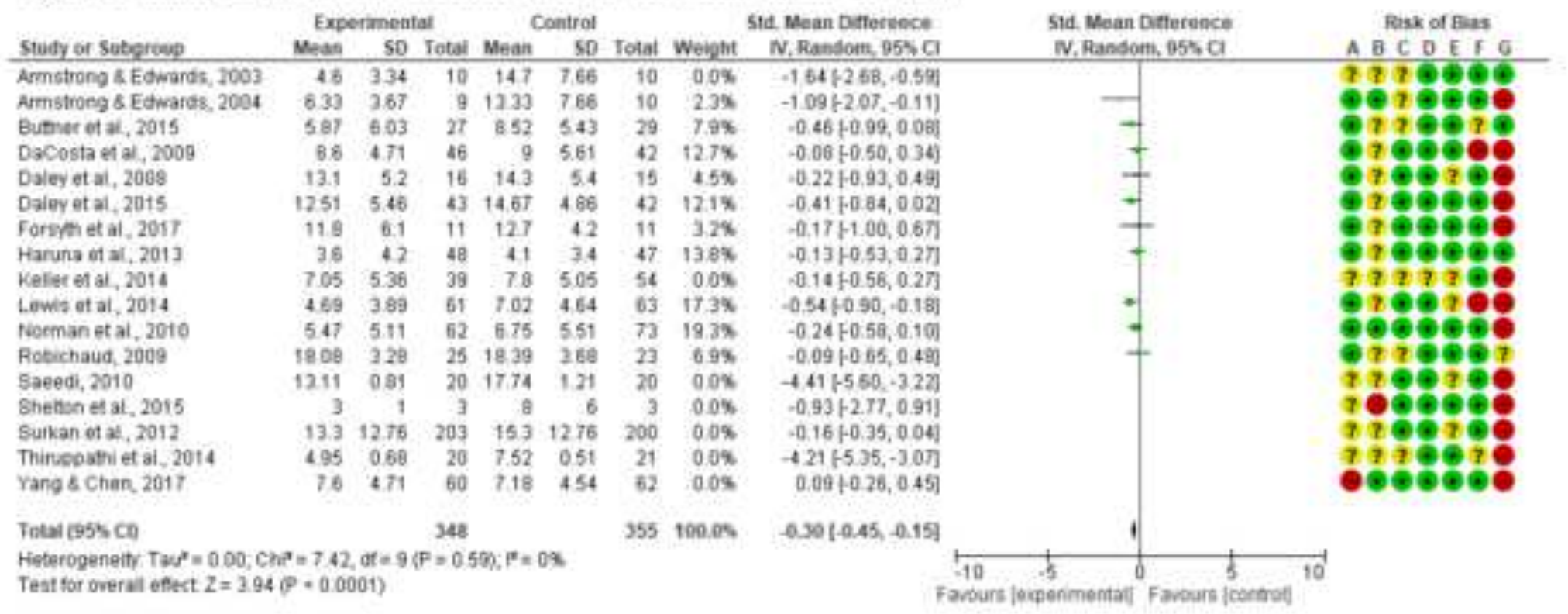


Figure 5: Post hoc sensitivity analysis following removal of outliers

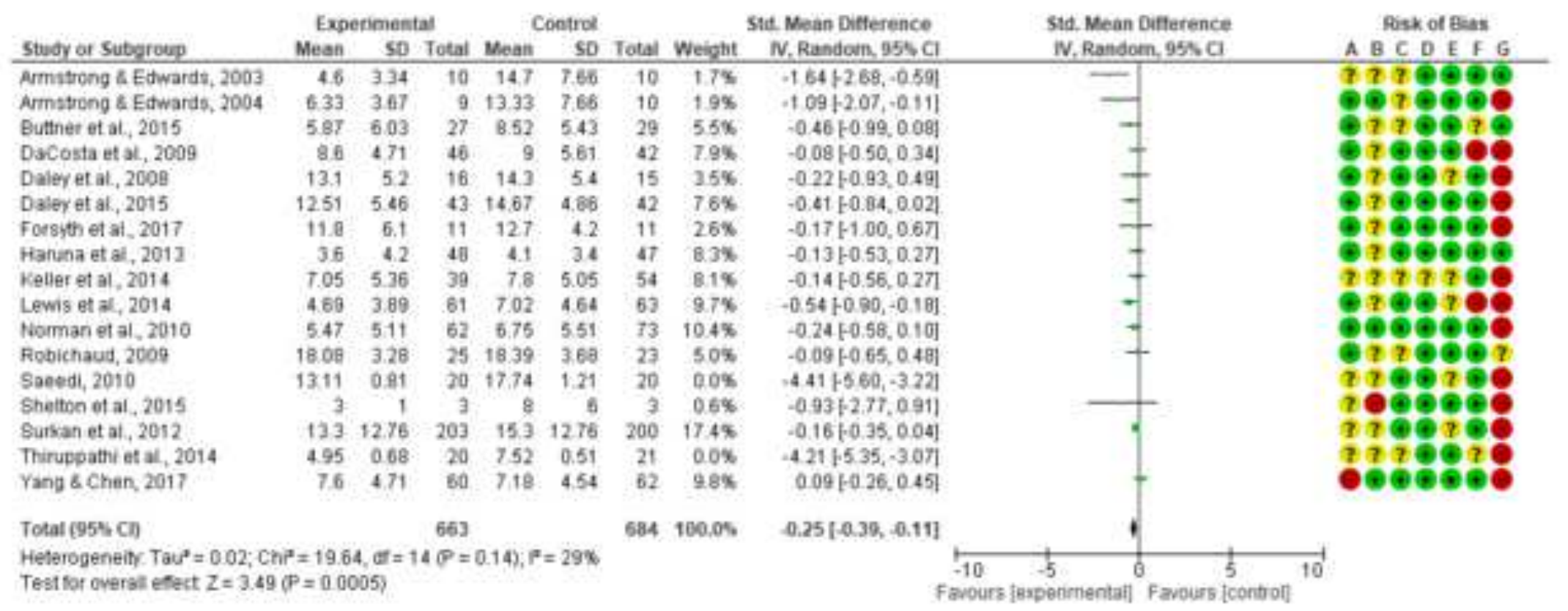

Helerogeneity Tat $\left.=0.02: \mathrm{Chi}^{\mathrm{P}}=19.64, \mathrm{Gf}=14 \mathrm{P}=0.14\right) ; \mathrm{F}=29 \%$ fest for overst efect $Z=3.49(\mathrm{P}=0.0005)$

Favours fespenimentali favours tcontiol? 
Figure 6: Subgroup analysis of universal and targeted interventions

\begin{tabular}{|c|c|c|c|c|c|c|c|c|c|c|}
\hline \multirow[b]{2}{*}{ Stuify or Sobgroup. } & \multicolumn{3}{|c|}{ Experamental } & \multicolumn{3}{|c|}{ Centrol } & \multicolumn{2}{|r|}{ sid. Mean boltereoce } & \multirow{2}{*}{$\begin{array}{l}\text { Sth. Mean Defterence } \\
\text { N. Random, } 95 \times C \text { I }\end{array}$} & Wisk of bias \\
\hline & Mean & so & Total & Mean & so & Totai & Weight & N. Handom, $95 \mathrm{Na}$ & & $A B C D E F G$ \\
\hline \multicolumn{11}{|l|}{ 2.1.1 tinversal } \\
\hline Hanua et al, 2013 & 3.6 & 4.2 & 46 & 4.1 & 34 & 47 & $7+8$ & $-0.13 f 0.52,0.27$ & 7 & \multirow{8}{*}{ 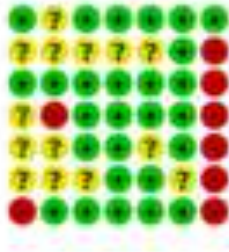 } \\
\hline Keller ef 4,2014 & 7.05 & 5.35 & 39 & 7.8 & 5.05 & 54 & 7.06 & $-0.14+0.56,0.2 n$ & 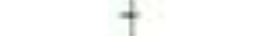 & \\
\hline Norman et at.2 2010 & 647 & 5.11 & 62 & 6.75 & 5,51 & 73 & 7.38 & $-0.24[0.50,0.106$ & & \\
\hline Shaton of ar, 2015 & 3 & 1 & 3 & $\theta$ & 5 & 3 & 2.38 & $-0.93+377,0911$ & & \\
\hline Sukvan et 21,2012 & 133 & 12.76 & 203 & 153 & 12.76 & 200 & 778 & $=0.16+0.35,0.04$ & & \\
\hline Thiruppathiet al, 2014 & 4.95 & 0.60 & 20 & 7.52 & 0.51 & 21 & $40 \mathrm{~s}$ & $-421 ;-5,35,-3.07$ & - & \\
\hline Yang 8 Chen, $201 Y$ & 7.6 & 4.71 & 60 & 7.18 & 4.54 & 62 & 7.26 & $0.09+0.26,0.45$ & & \\
\hline Sotbiotal (95N C) & & & 495 & & & 46 & 42.55 & $0.52[-0.90,-0.05]$ & 4 & \\
\hline \multicolumn{11}{|c|}{ 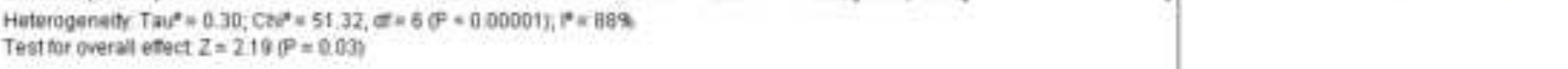 } \\
\hline \multicolumn{11}{|l|}{2.12 Tarpetes } \\
\hline Amstorig \& Edwarts, 2003 & 4.6 & 3.34 & 10 & 147 & 766 & 10 & 438 & $-1.54+2.68,-0.59$ & - & \multirow{11}{*}{ 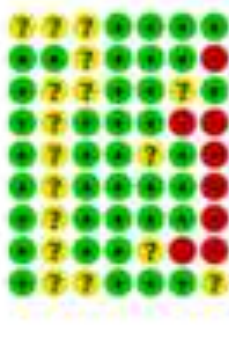 } \\
\hline Numstong s Eawards, 2004 & 633 & 3.67 & $\theta$ & 13.33 & 766 & 10 & $4.5 \%$ & $-109+207,-0111$ & $\rightarrow$ & \\
\hline Bather ef 4.2015 & 6.97 & 600 & 27 & 852 & 5.43 & 29 & 658 & -0.4650 .090 .005 & - & \\
\hline Dacosta et at, $200 \mathrm{a}$ & 2.6 & 471 & 46 & g & 5.61 & 42 & 7.08 & $-0.08[0.50 .0 .34$ & & \\
\hline Daigyet al _2008: & 131 & 52 & 16 & 143 & 5.4 & is & 578 & $=0.2210 .93,049$ & - & \\
\hline Daley at al, 2015 & 1251 & 546 & 43 & 14.67 & 486 & 42 & 708 & $=0.41$ fase, 0.02 & - & \\
\hline Fersyth of al 2017 & 118 & E. & 11 & 123 & 42 & 11 & 518 & $-0.17-1.00,0.57$ & - & \\
\hline Lents at al_.2044 & 4.69 & 3.89 & 61 & 7.02 & 264 & 63 & 7.25 & $-0.54+0.90,-0.16$ & - & \\
\hline Rotictaus 2009 & 1808 & 328 & 25 & 18.39 & 3.68 & 23 & 6.48 & $0.0950 .68,0.49$. & - & \\
\hline Seopdi et $2 ;, 2013$ & 13.11 & 0.85 & 20 & 17.74 & 1.21 & 20 & 389 & $-441 ; 5.60,-327$ & - & \\
\hline Suttotal $1955 \mathrm{Cm}$ & & & 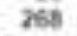 & & & 265 & 57.55 & $0.751-1.22,-0.281$ & $\bullet$ & \\
\hline
\end{tabular}




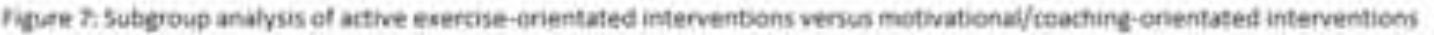

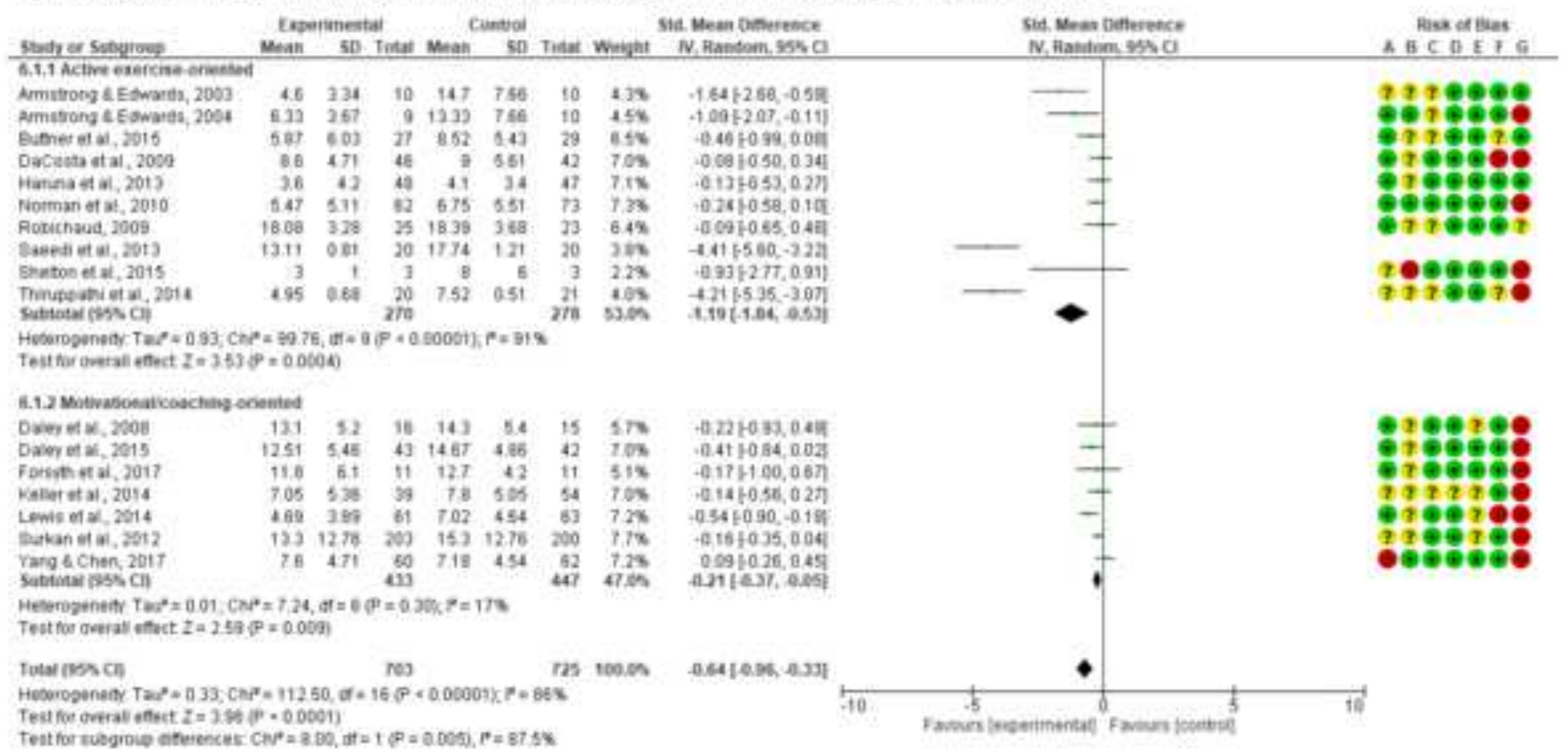

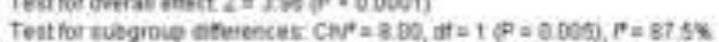
465094,000 $13+053,027$ $0910.55,04$ 려 ago,

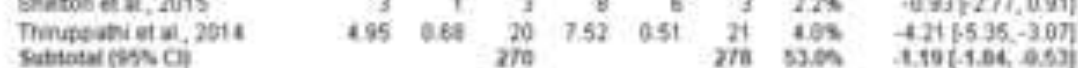

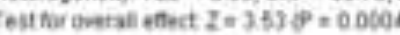

1.2 Mntivasonatcoschasgonente: 1251 5. 11.0
705 
Figure 8: Subgroug analysis of sfudies with active control conditions versus other control conditions

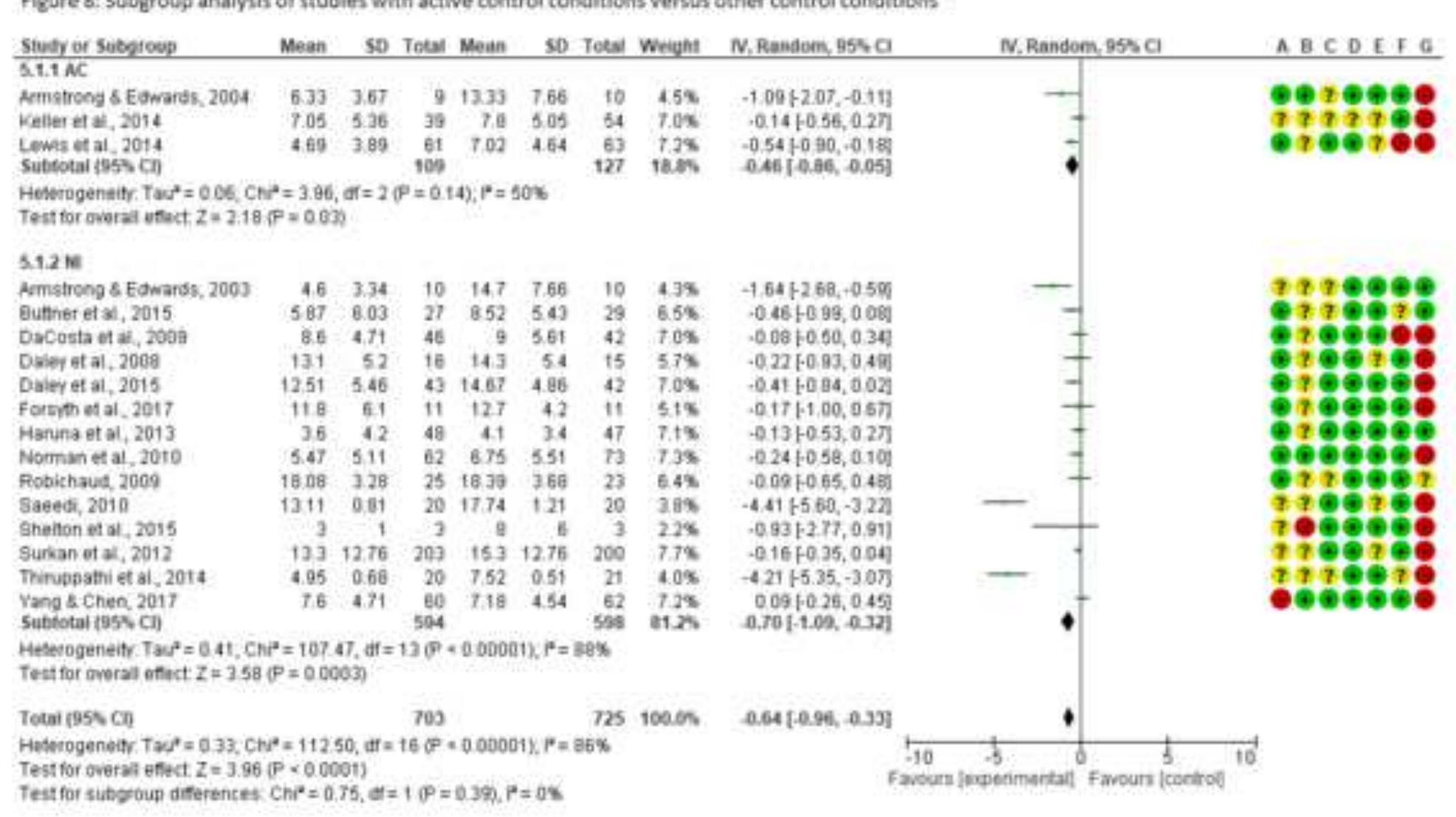

(2)

(1)

Terseng

(20)

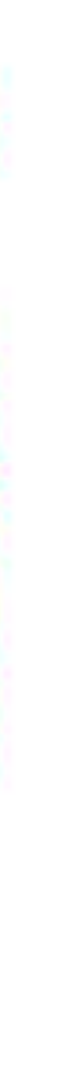


Figure 9: Subgroup analysis of short and long duration interventions

\begin{tabular}{|c|c|c|c|c|c|c|c|c|c|c|}
\hline \multirow[b]{2}{*}{ Study or Saboroup } & \multicolumn{3}{|c|}{ Experimental } & \multicolumn{3}{|c|}{ Coetrol } & \multicolumn{2}{|r|}{ Std. Mean Difference } & \multirow{2}{*}{$\begin{array}{l}\text { Sid. Mean Difference } \\
\text { IV, Random, } 95 s \mathrm{CI}\end{array}$} & Pisk of Bias \\
\hline & Mean & so & Total & Moan & SD & Total & Weight & N. Fandom, 95t C & & $A B C D E F G$ \\
\hline \multicolumn{11}{|l|}{2.3 .1 Short } \\
\hline Buther et al, 2015 & 587 & 6.03 & 27 & 8.52 & 5.43 & 29 & $65 \%$ & $-0.46+-0.99,0.081$ & - & $0 ? 700$ \\
\hline Norman et al, 2010 & 5.47 & 5,11 & 62 & 6.75 & 5,51 & 73 & $7.1 \%$ & $-024,-0.50,010]$ & & $\theta \theta \theta \theta$ \\
\hline Robichaud, 2009 & 18.08 & 3.28 & 25 & 28.39 & 3.88 & 23 & $5.4 \%$ & $-2.92+3.75,-2.081$ & - & 6? 790 \\
\hline Sheiton et al. 2015 & 3 & 1 & 3 & 8 & 6 & 3 & $26 \%$ & $-0.93-2.77,0.911$ & & \\
\hline Thirupgami et al, 2014 & 495 & 0.68 & 20 & 7,52 & 0.51 & 21 & $4.4 \%$ & $-421+535,-3.07$ & - & 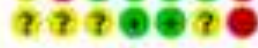 \\
\hline Subtotal ( $95 \mathrm{~S} \mathrm{Cl})$ & & & 137 & & & 149 & 26.05 & $-1.72[-3.05,-0.39)$ & & \\
\hline \multicolumn{11}{|c|}{$\begin{array}{l}\text { Heterogeneity Taut }=2.05 ; \text { Chip }=71.46, d f=4(P=0.00001) ; f^{*}=94 \% \\
\text { Test for overall effect } Z=2.53(P=0.01)\end{array}$} \\
\hline \multicolumn{11}{|l|}{$2.3 .2 \mathrm{Logg}$} \\
\hline Armstiong \& Edwatds, 2003 & 4.6 & 3.34 & 10 & 14.7 & 7.66 & 10 & $47 \%$ & $-1.64+2.68,-0.59 \mid$ & - & $37 ? 69$ \\
\hline Afmstrong s Edwards, 2004 & 633 & 3.67 & 9 & 13.33 & 7.66 & 10 & $4.9 \%$ & $-1.09+2.07,-0.111$ & & \\
\hline Dacosta et at, 2009 & 8.6 & 471 & 46 & 9 & 5.61 & 42 & 6.98 & $-0.08[-0.50,0.34]$ & & $=0$ \\
\hline Daler et al, 2008 & 13.1. & 5.2 & 16 & 14.3 & 5.4 & 15 & 5.96 & $=0.22+0.93,049]$ & - & 200 \\
\hline Daley at al, 2015 & 1251 & 5.46 & 43 & 14.67 & 486 & 42 & $6.8 \%$ & $-0,41+-0.84,0.024$ & - & 02060 \\
\hline Forsith et al, 2017 & 11.8 & 6.1 & 11 & 127 & 42 & 11 & $5.4 \%$ & $-0.17+1.00,0.67$ & - & 97096 \\
\hline Haruna ef al, 2013 & 36 & 42 & 48 & 4.1 & 3.4 & 47. & 6.94 & $-0.13[0.53,0.27)$ & & 07096 \\
\hline Lewas et al, 2014 & 4.69 & 3.89 & 61 & 7.02 & 4.64 & 63 & $7.0 \%$ & $-0.54+0.90,-0.18]$ & - & \\
\hline Sasedi et ai, 2013 & 13.11 & 0.81 & 20 & 17.74 & 121 & 20 & 426 & $-441+5.60,-3.221$ & & \\
\hline Surkan et al., 2012 & 13.3 & 12.76 & 203 & 15.3 & 12.76 & 200 & $7.4 \%$ & $-0.16[-0.35,0.04]$ & & $?$ \\
\hline Yang 8 Chen, 2017 & 7.6 & 4.71 & 60 & 7,18 & 4.54 & 62 & $70 \%$ & $0.09[0.26,0.45]$ & & \\
\hline Subtotal (95S Cl) & & & 566 & & & 576 & 74.05 & $-0.52[-0.84,-0.19]$ & $\bullet$ & \\
\hline \multicolumn{11}{|c|}{ 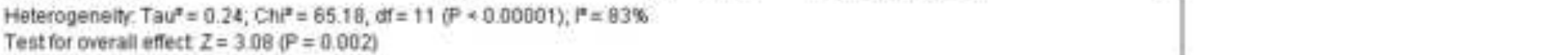 } \\
\hline
\end{tabular}


Figure 10: Funnel plot with all the included studies.

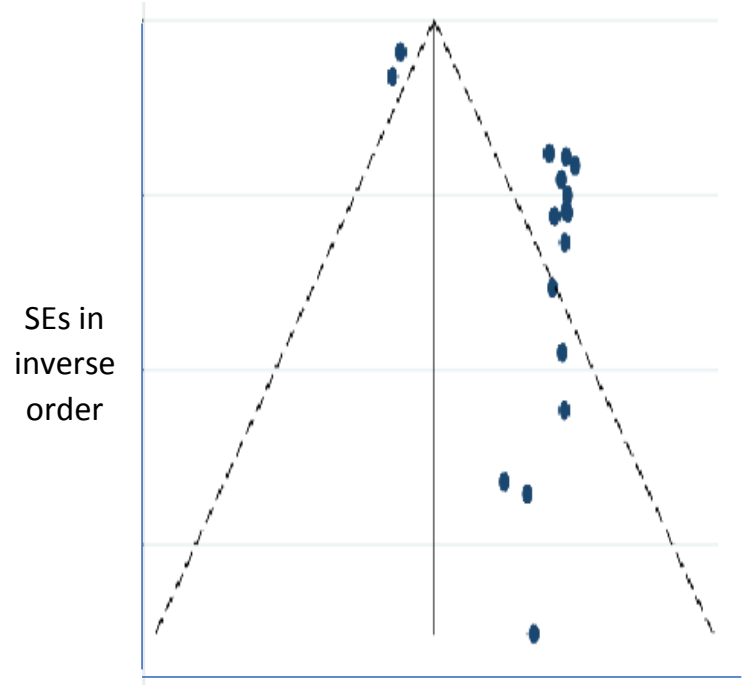

SMDs 
Figure 11: Funnel plot of the included studies after removing the two outlier-studies.

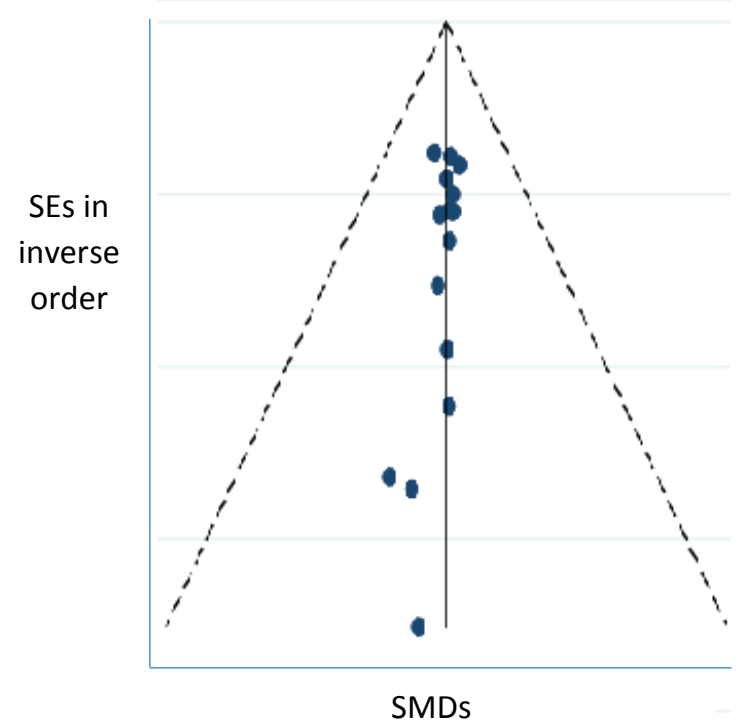


Click here to access/download Supplementary Material Supplementary file 1.docx 


\begin{abstract}
Click here to access/download
Supplementary Material
PRISMA checklist.docx
Click here to access/download
Supplementary Material
PRISMA checklist.docx

Click here to access/download
Supplementary Material
PRISMA checklist.docx

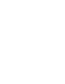

.

.

-

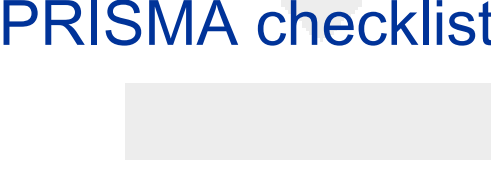


1 The effectiveness of exercise-based interventions for preventing or treating postpartum depression: a 2 systematic review and meta-analysis

3

\section{Abstract}

5 Purpose: Postpartum depression can have detrimental effects on both a mother's physical and mental health and on her child's growth and emotional development. The aim of this study is to assess the effectiveness of exercise/physical activity-based interventions in preventing and treating postpartum depressive symptoms in primiparous and multiparous women to the end of the postnatal period at 52 weeks postpartum. Methods: Electronic databases were searched for published and unpublished randomised controlled trials of exercise/physical activity-based interventions in preventing and treating depressive symptoms and increasing health-related quality of life in women from 4 to 52 weeks postpartum. The results of the studies were metaanalysed and effect sizes with confidence intervals were calculated. The Grading of Recommendations Assessment and Development and Evaluation (GRADE) system was used to determine the confidence in the effect estimates. Results: Eighteen trials conducted across a range of countries met the inclusion criteria. Most of the exercise interventions were aerobic and coaching compared to usual care, non-intervention and active controls. Small effect sizes of exercise-based interventions in reducing depressive symptoms were observed collectively and the quality of evidence was low across the individual studies. Discussion and conclusions: Although exercise-based interventions could create an alternative therapeutic approach for preventing major depression in postpartum women who experience subthreshold elevated depressive symptoms, the clinical effectiveness and the cost-effectiveness of exercise-based and physical activity interventions need to be better established. There is a need for further, more rigorous testing of such interventions in high-quality randomised controlled trials against active control conditions before large-scale roll-out of these interventions in clinical practice is proposed.

\section{Introduction}

About $20 \%$ of women globally experience a perinatal mental health disorder, mainly depression and anxiety, when they are pregnant or in the perinatal period up to 52 weeks after they have given birth (WHO 2017). The most severely affected women can develop self-harm and suicidal ideations (Pope et al 2013; Wisner et al 2013). Perinatal anxiety and depression can compromise the long term growth and development of the baby (FaríasAntúnez et al 2017), with long term costs of £8.1bn (Bauer et al 2014). A range of physical, genetic and socioeconomic factors put pregnant and postpartum women at risk of perinatal mental health problems whilst buffering factors (e.g. supportive partner) are protective (Austin et al 2010). 
In the United Kingdom early psychosocial or pharmacological interventions are recommended to reduce the prevalence of perinatal anxiety and depression, to benefit women and families, and reduce costs (Morrell et al 2009; NICE 2014; Morrell et al 2016; Saligheh et al 2017).

The perinatal period is also characterised by difficulty in managing weight and engaging in physical activity (Gaston \& Cramp 2013). A reduction in physical activity/exercise throughout pregnancy can lead to lower selfratings of quality of life (Campolong 2017) and can have detrimental effects on physical health (Fazzi, Saunders, Linton, Norman, \& Reynolds 2017). Sedentary behaviours have been associated with increased risk for postnatal depressive symptoms, whereas physical activity in pregnancy and postnatally has been associated with decreased risk for developing depressive symptoms (Claesson, Klein, Sydsjo, \& Josefsson 2014; Teychenne \& York 2013). Given that engaging in sedentary behaviours during pregnancy can be continued postpartum, exercise-based interventions could yield multi-tiered benefits for the physical and mental health of perinatal women.

Small to moderate effects on depression symptoms have been found from exercise-based interventions in adults and young people (Standardised Mean Difference [SMD] -0.62, 95\% Confidence Interval [CI] -0.81, -0.42), compared to control conditions (Cooney et al 2013; Carter et al 2016). In postpartum populations, there is a promising evidence base for exercise-based interventions in preventing and treating depressive symptoms (McCurdy et al 2017; Poyatos-León et al 2017). The content of these interventions covers aerobic activities, stretching, yoga and exercise-based coaching. In randomised controlled trials (RCTs), exercise-based interventions have been compared to control conditions of usual care (UC) or non-intervention (NI), but few have been compared against active control (AC) or wait list control (WLC) (Armstrong \& Edwards 2004; LeCheminant et al 2014). Most exercise-based interventions have been tested in targeted populations, such as women with elevated depression symptoms (Buttner et al 2015) or women with a previous history of depression (Lewis et al 2014).

There is now a need for a robust evidence synthesis that follows methodologically rigorous processes (Saligheh et al 2017) to systematically identify the components and characteristics of interventions, and analyse their effectiveness, to promote the development of beneficial exercise-based interventions in clinical practice (Saligheh et al 2017). 
63 This review aims to synthesise evidence from randomised controlled trials (RCTs) for the clinical effectiveness

64 of exercise-based interventions compared to all types of control in preventing and treating depressive symptoms

65 in primiparous and multiparous women from the possible onset at 4-6 weeks postnatally (Putman et al 2017), to the end of the postpartum period (12 months after the birth of the baby). Additionally, this review aims to identify factors associated with the effectiveness of exercise-based interventions, testing the moderating effects of the intervention's: scope (universal vs. targeted); content (strongly exercise-oriented vs. exercise consulting and coaching); duration (short vs. long duration); and control condition: active control (AC) vs. usual care (UC), nonintervention (NI), and wait list control (WLC).

\section{Methods}

The protocol of this systematic review and meta-analysis was registered with PROSPERO (2017:CRD42017068376) and the presentation of the findings conforms to PRISMA (Moher et al 2009). The primary outcome was depression symptoms in postpartum women at post intervention and the secondary outcomes were symptoms of anxiety and health-related quality of life (HRQoL).

\section{Inclusion criteria:}

Population: primiparous or multiparous postnatal women.

Intervention: exercise-based (supervised, unsupervised, coaching-based, motivational, behavioural-oriented, universal, targeted or treatment based, in a community or clinical context).

Comparison: any type of control condition (e.g. flexibility/stretching or social support sessions, UC, NI, AC, WLC).

Outcomes: depression symptoms using a validated assessment tool (e.g. Edinburgh Postnatal Depression Scale (EPDS), Patient Health Questionnaire).

Study type: published or unpublished individual RCTs or cluster RCTs.

\section{Exclusion criteria:}

Population: pregnant women; women with psychiatric diagnoses other than depression.

Intervention: no details of the exercise component; intervention delivered before 4 weeks or after 52 weeks.

Comparison: no comparison interventions were excluded. 
92

93

94

95

96

97

98

99

100

101

102

103

104

105

106

107

108

109

110

111

112

113

114

115

116

117

118

119

120

Outcomes: no depression symptom measure; outcomes before 4 weeks postpartum.

Study type: non RCTs.

Search Strategy

Libraries and databases searched for papers published between 1974 and June 2017 were: Allied and Complementary Medicine Database (AMED), Applied Social Sciences Index and Abstracts (ASSIA), Cumulative Index to Nursing and Allied Health Literature (CINAHL), Current Controlled Trials, EMBASE (Excerpta Medica), ISRCTN Register, MEDLINE (including PubMed), National Institute for Health Research Health Technology Assessment (NIHR HTA) programme databases, PROSPERO, PsycINFO, Scopus, Science Citation Index and Conference Proceedings (Web of Science), The Cochrane Library (Cochrane Database of Systematic Reviews, Database of Abstracts of Reviews of Effects, Cochrane Central Register of Controlled Trials), World Health Organisation's International Clinical Trials Registry Platform (ICTRP). Online databases of grey literature searched, were: clinicaltrials.gov, International Standard Randomised Controlled Trials Number (ISRCTN) Register, OpenGrey, and ProQuest Dissertations \& Theses (PQDT).

The search strategy incorporated Medical Subject Heading (MeSH) terms in five areas:

Population: Postpartum Period; and Pregnant women/ OR Postnatal care/ OR Perinatal care. Depression/ OR Depression, Postpartum/; Anxiety/ OR Anxiety Disorders/

Intervention: Exercise Test/ OR Exercise/ OR Exercise Therapy/ OR Exercise Movement Techniques/

Outcome: Depression/ OR Depression, Postpartum/; Anxiety/ OR Anxiety Disorders/

Study type: The search was optimised using the 'RCTs (plus cluster)' clinical search filter recommended by the Centre for Reviews and Dissemination (CRD 2009).

Hand-searches of public online databases and contacts with field experts were also conducted. Three syntax sets were used in combination with the MeSH terms above for searching Medline, EMBASE and PsycINFO (See Table 1). 
Relevant authors were contacted when: full text articles were not available; there was insufficient information

122

123

124

125

126

127

128

129

130

131

132

133

134

135

136

137

138

139

140

141

142

143

144

145

146

147

148 provided for the inclusion criteria to be applied; there were insufficient details reported on the outcomes. Lack of reply from authors led to one study being included only in the qualitative synthesis: (LeCheminant et al 2014).

Following initial screening of titles and abstracts, full texts of all potentially relevant studies were assessed for inclusion independently by two reviewers (TC \& AB). Disagreements were resolved by discussion, or a third reviewer (JM) was consulted. Reference lists of included articles were searched for potentially eligible studies.

\section{Data Extraction}

Adapted versions of the Effective Practice and Organisation of Care (EPOC) Review Group data abstraction form and the Cochrane Collaboration Form for extracting data from RCTs were used to extract data from included studies. Two reviewers (TC \& AB) extracted data independently and disagreements were resolved by discussion between the two reviewers who presented their arguments to each other until agreement was made. A third reviewer (JM) would have been the final arbiter, but this process was not required at any point in this review. Extracted data included information on: study authors, participant demographic characteristics, intervention and control conditions, study method, recruitment and completion rates, outcomes and measurement times, information for assessment of risk of bias and quality. Experimental conditions were coded as either (a) intervention: exercise or physical activity, yoga, coaching sessions with exercise, social support with exercise or (b) control: UC, AC (social support sessions) NI, WLC.

\section{Quality assessment}

The quality of included studies was assessed using the Cochrane Collaboration tool for assessing risk of bias (Higgins et al 2011). Within each specified domain, adequate reporting resulted in a rating of low risk of bias, whereas evidence of bias resulted in a rating of high risk of bias. When insufficient detail was reported for clear assessment, a rating of unclear risk of bias was given. There was also an assessment of any additional threats of bias. Two researchers (TC \& AB) independently rated the risk of bias for each included study. Any disagreements were resolved after discussion. The Grading of Recommendations Assessment and Development and Evaluation (GRADE) system was used to assess confidence in the quality of evidence of individual outcomes and the strength of recommendations (Guyatt et al 2008). 
Data analysis was performed using RevMan Version 5.3 (Nordic Cochrane Centre 2014) and STATA Version 14

153 (StataCorp 2015). Standardised mean differences were computed for all included studies. Post-intervention effect sizes were computed, comparing the intervention arms of the studies to all types of control. Mean differences in the primary outcome (depression symptoms) were computed to Hedge's g. Hedge's g was obtained by subtracting control mean by intervention mean, divided by their pooled standard deviation and implementing the correction factor J (Borenstein et al 2009). Given the heterogeneity of methodologically diverse studies, a random effects model was adopted. Four subgroup analyses were pre-planned and conducted: 1) universal vs targeted interventions; 2) active exercise-orientated interventions vs non-active exercise-orientated; 3) studies using active control groups vs studies using other control groups; 4) interventions of longer duration vs interventions of shorter duration.

\section{Results}

The search yielded 20,671 abstracts following the removal of duplicates. Screening of title and abstracts resulted in 103 full texts articles undergoing eligibility assessment, of which 18 were included in the review, and 17 in the meta-analysis. Figure 1 presents a PRISMA Flow Chart illustrating study selection.

\section{Insert Figure 1}

Table 2 presents a summary of the 18 studies included in the qualitative synthesis. Seventeen studies were included in the meta-analysis: three each from Australia (Armstrong \& Edwards 2003; Armstrong \& Edwards 2004; Norman et al 2010), and the UK (Daley et al 2008; Daley et al 2015; Forsyth et al 2017), six from the USA (Buttner et al 2015; Keller et al 2014; Lewis et al 2014; Robichaud et al 2009; Shelton et al 2015; Surkan et al 2012), one each from Canada (DaCosta et al 2009), Japan (Haruna et al 2013), Iran (Saeedi 2013), Taiwan (Yang \& Chen 2017), and India (Thiruppathi et al 2014). 

(Armstrong \& Edwards 2003; Daley et al 2008; Forsyth et al 2017; Shelton 2015; Yang \& Chen 2017). The number of participants ranged from 20 to 160; whilst one study had 679 participants. Apart from two included theses (Robichaud et al 2009; Shelton 2015), the studies were published in peer reviewed academic journals.

A targeted prevention approach was used in 10 studies, to target at-risk women with a history of depression or elevated depression symptoms (Armstrong \& Edwards 2003; Armstrong \& Edwards 2004; Buttner et al 2015; DaCosta et al 2009; Daley et al 2008; Lewis et al 2014; Robichaud et al 2009; Saeedi 2013). A universal prevention approach (targeted at a whole population that has not been identified on the basis of individual risk) was tested in eight studies (Haruna et al 2013; Keller et al 2014; Norman et al 2010; Shelton et al 2015; Thiruppathi et al 2014; Yang \& Chen 2017). Two studies tested a treatment approach for women with postpartum depression (Daley et al 2015; Forsyth et al 2017).

192

In six studies, participants' baseline depression symptoms were mild (Keller et al 2014; Lewis et al 2014; Norman et al 2010; Shelton et al 2015; Thiruppathi et al 2014; Yang \& Chen 2017). In two studies participants' symptoms were mild to moderate (Buttner et al. 2015; DaCosta et al. 2009); in five studies, symptoms were moderate (Armstrong \& Edwards 2003; Armstrong \& Edwards 2004; Daley et al 2015; Forsyth et al 2017; Surkan et al 2012), and in three studies symptoms were moderate to severe (Daley et al 2008; Robichaud et al 2009; Saaei 2013).

\section{Intervention and control conditions}

201

Most studies compared the intervention arm to a NI or UC control condition, with four studies using an AC comparison (Armstrong \& Edwards 2004; Keller et al 2014; LeCheminant et al 2014; Lewis et al 2014). See Table 3 for an overview of intervention characteristics in each study.

In eight studies, the interventions tested were of aerobic and/or strengthening and/or muscle stretching content (Armstrong \& Edwards 2004; Buttner et al 2015; Haruna et al 2013; LeCheminant et al 2014; Robichaud 2009; Saaedi 2013; Shelton 2015; Yang \& Chen 2017). In four studies the content was coaching and motivational health promotion techniques and no exercise (Daley et al 2015; Daley et al 2008; Lewis et al 2014; Surkan et al 2012). 
techniques (Armstrong \& Edwards 2003; DaCosta et al 2009; Forsyth et al 2017; Keller et al 2014; Norman et al 2010; Thirrupathi et al 2014).

The duration of $76 \%$ (13/17) interventions was up to 12 weeks; with four studies testing interventions for longer than 12 weeks (Daley et al 2015; LeCheminant et al 2014; Lewis et al 2014; Surkan et al 2012). The duration of the supervised delivered sessions ranged from 30 to 90 minutes, with most sessions delivered at moderate intensity. The frequency of the sessions delivered per week across the interventions ranged from one to four.

Six studies were of supervised interventions (Armstrong \& Edwards 2003; Haruna et al 2013; Keller et al 2014; Norman et al 2010; Saeedi 2013; Thiruppathi et al 2014); seven studies were of non-supervised interventions (Daley et al 2015; Daley et al 2008; Lewis et al 2014; Robichaud 2009; Shelton 2015; Surkan et al 2012; Yang \& Chen 2017); and five studies were of both supervised and non-supervised elements (Armstrong \& Edwards 2004; Buttner et al 2015; DaCosta et al 2009; Forsyth et al 2017; LeCheminant et al 2014).

Of the supervised interventions six were delivered by qualified service providers (Buttner et al 2014; DaCosta et al 2009; Haruna et al 2013; LeCheminant et al 2014; Norman et al 2010; Thiruppathi et al 2014); four were delivered by non-qualified service providers (Armstrong \& Edwards 2003; Armstrong \& Edwards 2004; Keller et al 2014; Saeedi et al 2013); and one did not report provider information (Forsyth et al 2017). Table 3 presents an overview of intervention characteristics for each study.

\section{Insert Table 3}

Outcomes

Depression symptoms were assessed using the EPDS in most studies. Two studies used the The Center for Epidemiological Studies-Depression (CES-D) (Surkan et al 2012; LeCheminant et al 2014) and one study used the Hamilton Rating Scale for Depression (HRSD) (Buttner et al 2015). HRQoL was measured in three studies using the 36-Item Short-Form Health Survey (Buttner et al 2015; Daley et al 2015; Haruna et al 2013) and anxiety 2015). 
241 Figure 2 presents the ratings for each item of the risk of bias assessment tool. Overall, most of the RCTs were of 242 low to moderate quality. "Other risk of bias" was identified in multiple studies and was caused by: i. uncertainty about ITT analysis in five studies (Daley et al 2008; Norman et al 2010; Thiruppathi et al 2014; Yang \& Chen 2017) and ii. potential threat of unsuccessful randomisation in one study (Daley et al 2015). "Unclear risk of bias" was identified in multiple studies caused by: i. insufficient details of the allocation concealment procedures and ii. insufficient details regarding the sequence generation methods (five studies). There was poor reporting of the outcomes in two of the studies (Saeedi 2013; Thirrupathi et al 2014) leading to a rating of high risk of bias. Given the nature of intervention and control conditions, a complete blinding procedure was impossible, however, given the outcome was self-report in most of the studies, they were generally rated as low-risk in the "blinding" sections of the risk of bias tool. Studies that reported an intention-to-treat analysis were rated as low-risk of bias (Higgins et al 2011).

Insert Figure 2

Meta-analysis

A moderate, significant, standardised mean difference (SMD), favouring the intervention condition, was found for depressive symptoms, SMD $=-0.64,95 \% \mathrm{CI}=[-0.96,-0.33], \mathrm{p}<0.001$ (see Figure 3 for forest plot including all studies and the bias-adjusted Hedge's g effect sizes). A non-significant SMD, favouring the intervention condition, was found for secondary outcomes: physical function, $\mathrm{SMD}=-0.04,95 \% \mathrm{CI}=[-0.33,0.26], \mathrm{p}=0.81$; and a non-significant SMD, favouring the control condition, was found for mental function, SMD $=0.27,95 \% \mathrm{CI}$ $=[-0.03,0.56], \mathrm{p}=0.07$. Due to the dearth of data, effect sizes for anxiety were not calculated.

\section{Insert Figure 3}

Sensitivity analyses

Results of the sensitivity analyses showed a small, significant effect on depression, favouring the intervention condition, $\mathrm{SMD}=-0.30,95 \% \mathrm{CI}=[-0.45,-0.15], \mathrm{p}<0.001$ (Armstrong \& Edwards 2004; Buttner et al 2015; DaCosta et al 2009; Daley et al 2008; Daley et al 2015; Forsyth et al 2017; Haruna et al 2013; Lewis et al 2014; 
of the exercise-based interventions after removing the two outlying studies (Saaedi 2013; Thirrupathi et al 2014). This post-hoc sensitivity analysis yielded small, significant, results $(\mathrm{SMD}=-0.25,95 \% \mathrm{CI}=[-0.39,-0.11], \mathrm{p}=$ 0.0005) (see Figure 5).

\section{Insert Figure 4 and Figure 5}

\section{Subgroup analyses}

A comparison of the effectiveness of universal prevention interventions (Haruna et al 2013; Keller et al 2014; Norman et al 2010; Shelton 2015; Surkan et al 2012; Thiruppathi et al 2014; Yang \& Chen 2017) versus targeted prevention or treatment interventions (Armstrong \& Edwards 2003; Armstrong \& Edwards 2004; Buttner et al 2015; DaCosta et al 2009; Daley et al 2008; Daley et al 2015; Forsyth et al 2017; Lewis et al 2014; Robichaud 2009; Saeedi 2013) was conducted. Targeted prevention or treatment interventions yielded a greater effect size compared to universal prevention interventions $(\mathrm{SMD}=-0.75,95 \% \mathrm{CI}=[-1.22,-0.28], \mathrm{p}=0.002$ for the targeted interventions and SMD $=-0.52,95 \% \mathrm{CI}=[-0.99,-0.05], \mathrm{p}=0.03$ for universal prevention interventions) (See Figure 6).

A comparison of the effectiveness of interventions with an active exercise-oriented component (Armstrong \& Edwards 2003; Armstrong \& Edwards 2004; Buttner et al 2015; DaCosta et al 2009; Haruna et al 2013; Norman et al 2010; Robichaud 2009; Saeedi 2013; Shelton 2015; Thiruppathi et al 2014) versus those with coaching/motivational components (Daley et al 2008; Daley et al 2015; Forsyth et al 2017; Keller et al 2014; Lewis et al 2014; Surkan et al 2012; Yang \& Chen 2017) was conducted. Interventions with active exerciseoriented components yielded larger effects than those with coaching/motivational components $(\mathrm{SMD}=-1.19$, $95 \% \mathrm{CI}=[-1.84,-0.53], \mathrm{p}=0.0004$ for active exercise interventions and $\mathrm{SMD}=-0.21,95 \% \mathrm{CI}=[-0.37,-0.05]$ $\mathrm{p}=0.009$ for coaching/motivational interventions (See Figure 7).

(1)

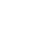



$95 \% \mathrm{CI}=[-1.09,-0.32], \mathrm{p}=0.0003)($ See Figure 8$)$.

\section{Insert Figure 8}

305

A comparison of interventions with long duration (12 weeks or more) versus interventions with a shorter duration (fewer than 12 weeks) was conducted. Interventions with shorter duration (SMD $=-1.72,95 \% \mathrm{CI}=[-3.05,-0.39]$, $p=0.01)$, yielded a larger effect sizes than those of longer duration $(\mathrm{SMD}=-0.52,95 \% \mathrm{CI}=[-0.84,-0.19], \mathrm{p}=$ 0.002) A meta-regression for the effect of duration on effect sizes of these interventions was performed with no significant results $(\beta=0.07,95 \% \mathrm{CI}=[-0.11,0.25], \mathrm{p}=0.415)($ See Figure 9).

Heterogeneity

Heterogeneity was high in the main analysis $\left(\mathrm{I}^{2}=86 \%\right.$, Tau $\left.{ }^{2}=0.33, \mathrm{df}=16, \mathrm{p}<0.0001\right)$ but was eliminated in the sensitivity analysis $\left(\mathrm{I}^{2}=0 \%, \mathrm{Tau}^{2}=0, \mathrm{df}=9, \mathrm{p}=0.59\right)$ where studies with no clear reporting of randomisation procedure were excluded.

\section{Publication bias}

Inspection of the funnel plot for the main analysis revealed extensive asymmetry (see Figure 10 and Figure 11 for the funnel plot and the contour-enhanced funnel plot), indicating potential threat for publication bias. An Egger's test was performed (Egger et al 1997) for testing the funnel plot's asymmetry, indicating statistically significant results for small-study effects $(\beta=-4.72,95 \% \mathrm{CI}=[-5.44,-4.00], \mathrm{p}=0.000)$. However, after the two outlier studies were excluded, the Egger's test did not retain statistical significance $(\beta=-0.08,95 \% \mathrm{CI}=[-0.29,0.45], \mathrm{p}$ $=0.647)$.

\section{Insert Figure 10 and Figure 11}


Due to the dearth of data on secondary outcomes, the quality of evidence was assessed only for the primary outcome. Table 4 is a summary of findings ( $\mathrm{SoF}$ ) table that presents the comparison between exercise/physical activity-based interventions against all types of controls (AC, NI, UC, WL) in reducing depression symptoms. SMD is re-expressed as Mean Difference (MD) using a familiar instrument, the EPDS, in order to facilitate clinical interpretation (Ryan, Sontensso, \& Hill 2016; Schunemann et al 2008). To do so, a pooled standard deviation for EPDS scores was obtained from a cluster RCT (Morrell et al 2009) in order to transform SMD to MD. A small to moderate effect of exercise-based interventions to reduce depressive symptoms was found. We did not downgrade the quality of evidence regarding publication bias, given that the Egger test was non-significant after removing the two outlier studies (Saeedi 2013; Thirruppathi et al 2014). However, since 76\% (13/17) of the studies did not report a clear allocation concealment method, $41 \%$ (7/17) studies reported inadequate methods for sequence generation, and it was unclear whether some of the studies followed an ITT analysis, the quality of evidence was downgraded one level in the risk of bias section. In addition, the confidence intervals in most of the studies crosses \pm 0.50 , leading to the downgrading of the quality of evidence regarding the imprecision of effects (Ryan \& Hill 2016). The downgrading of the evidence was undertaken in accordance with established guidance (see Balshem et al 2011). Consequently, the downgrading in two categories led to a low rating of the quality of evidence regarding the effectiveness of exercise-based interventions in reducing depression symptoms in postpartum women (Ryan \& Hill 2016). Additionally, the transformation of SMD to MD, using a population-based SD for EPDS scores, highlighted that this mean difference does not signify a clinically significant difference (Matthey 2004). In summary, our confidence in the effect estimate for depression symptoms is limited: The true effect may be substantially different from the estimate of the effect.

\section{Insert Table 4}

\section{Discussion}

This meta-analysis found a statistically significant moderate treatment effect ( $\mathrm{SMD}=-0.64)$ of exercise over control conditions for depression symptoms in postpartum women up to 52 weeks after childbirth. Due to high levels of heterogeneity $\left(I^{2}=86 \%\right)$, a sensitivity analysis was conducted excluding the studies with a high risk of bias. This analysis eliminated heterogeneity, however reduced the magnitude of effect to small $(\mathrm{SMD}=-0.30)$, suggesting a consistent yet reduced effect of exercise for depression symptoms in postpartum women. 
As the postpartum period can pose problems for managing weight in non-lactating women and for maintaining physical activity (Gaston \& Cramp 2013), the introduction of an exercise intervention is likely to have additional physical benefits alongside the effect of reducing symptoms of depression. Qualitative evidence suggests that additional benefits of exercise are improved confidence, body image, and mood (Pritchett et al 2017). Moreover, when lactating women are reluctant to take anti-depressant medication (Turner et al 2008) exercise provides an acceptable alternative.

Subgroup analyses revealed that exercise-based interventions targeting at-risk women with a history of depression or elevated depression symptoms postpartum yielded increased treatment effects than universal preventive interventions. A similar finding has been reported previously in the postpartum population (McCurdy et al 2017), and in young people (Carter et al 2016), thus suggesting exercise interventions may be best applied as either a targeted preventive or treatment intervention. However, when exercise could be most efficacious, it is paradoxically when an individual might be less likely to undertake exercise due to the physical symptoms of depression (i.e. fatigue, diminished concentration, disturbed sleep and appetite) understandably adversely affecting motivation and activity levels. Consequently, future studies testing exercise for postpartum women with elevated depression symptoms need to focus on how to maximise appeal of the intervention and target motivation.

Importantly, the majority of the included studies did not assess anxiety symptoms despite the well evidenced comorbidity of anxiety and depression in the post-partum period (Falah-Hassani, Shiri \& Denni 2016). Interestingly, this is not confined to exercise interventions as there is a reported general lack of research testing the efficacy/effectiveness of treatments for postnatal anxiety (Field 2018). As such, future studies should pay more attention to assessing and measuring symptoms of anxiety in pregnant and postnatal women with depression symptoms.

\section{Strengths and limitations}

This review has a number of strengths: (a) it is the first to include four RCTs of exercise for postpartum women that have not been previously included in qualitative and/or quantitative syntheses (Forsyth et al 2017; LeCheminant et al 2014; Thirruppathi et al 2014; Yang \& Chen 2017) (b) it includes only RCTs, thus recommendations are based on the best quality available evidence; (c) all subgroup analyses undertaken included a sufficient number of studies, thus reducing the likelihood of making spurious recommendations; (d) it is the first 
in this area to follow the GRADE approach for rating the quality of evidence; (e) The reporting conforms to

PRISMA guidance; and (f) the review has a prospectively registered protocol.

391

392

After careful inspection of the funnel plots, and without excluding the possibility of the publication bias, we assume that the poor methodological quality of smaller studies in this review has led to spuriously inflated effects (Sterne et al 2008). The conclusions of the review are limited by the number and quality of the included studies. Although adequate numbers of participants were included to detect a difference in SMD as was found, the small number of studies limits the subgroup analysis possible. Moreover, due to the dearth of data on anxiety symptoms no analysis was possible. In addition, the findings regarding the effects of exercise on HRQoL is limited, given that only two studies were included in the meta-analysis (Daley et al 2015; Haruna et al 2013). Finally, the overall low quality of the evidence limits the strength of the conclusions made.

400

401

\section{Quality of evidence}

402

The overall quality of evidence for exercise in depression symptoms in postpartum women is low, and our sensitivity analysis, which excluded studies at risk of selection bias, yielded a small treatment effect. Thus, the evidence does not currently support the large scale roll out of exercise interventions in treating and/or preventing depression symptoms in postpartum women.

406

\section{Conclusion}

Exercise is effective in reducing depression symptoms in postpartum women, however the effect size is small to moderate, and is based on mostly small, low quality RCTs. The sensitivity analysis produced zero heterogeneity $\left(\mathrm{I}^{2}=0 \%\right)$, and retained statistical significance, thus exercise as an intervention for postpartum depression symptom reduction certainly holds promise. Such an exercise intervention might be most effective for women with elevated symptoms of depression, and delivered with increased focus on active engagement in supervised exercise sessions.

However, there is need for high quality, sufficiently powered RCTs comparing exercise interventions against active controls. In addition, economic evaluations should be conducted in tandem with RCTs in order to assess the cost-effectiveness of exercise interventions for depression symptoms in postpartum women. 
Armstrong K, Edwards H (2003) The effects of exercise and social support on mothers reporting depressive symptoms: a pilot randomized controlled trial. International Journal of Mental Health Nursing, 12(2), 130-138.

Armstrong K., Edwards H (2004) The effectiveness of a pram-walking exercise programme in reducing depressive symptomatology for postnatal women. International Journal of Nursing Practice, 10(4), 177-194.

Austin MP, Hadzi-Pavlovic D, Priest SR, Reilly N, Wilhelm K, Saint K, Parker G (2010) Depressive and anxiety disorders in the postpartum period: how prevalent are they and can we improve their detection? Arch Womens Ment Health, 13(5), 395-401. doi:10.1007/s00737-010-0153-7.

Balshem H, Helfand M, Schunemann HJ, Oxman AD, Kunz R, Brozek J, Vist GE, Falck-Ytter Y, Meerpohl J, Norris S, et al. (2011) GRADE guidelines: 3. Rating the quality of evidence. J Clin Epidemiol. 64(4), 401-6.

Bauer A, Parsonage M, Knapp M, Lemmi V, Bayo A (2014) Costs of perinatal mental health problems. London School of Economics and Political Science, London, UK. Borenstein M, Hedges L, Higgins J, Rothstein H (2009) Introduction to meta-analysis. Chichester, UK: Wiley. Boyce P, Stubbs J, Todd A (1993) The Edinburgh Postnatal Depression Scale: validation for an Australian sample. Aust N Z J Psychiatry 27(3), 472-476. doi:10.3109/00048679309075805

Buttner MM., Brock RL, O'Hara MW, Stuart S (2015) Efficacy of yoga for depressed postpartum women: A randomized controlled trial. Complement Ther Clin Pract 21(2), 94-100. doi:10.1016/j.ctcp.2015.03.003 exercise during pregnancy with trimester-specific and postpartum quality of life and depressive symptoms in a cohort of healthy pregnant women. Arch Womens Ment Health. doi:10.1007/s00737-017-0783-0 from: http://www.crd.york.ac.uk/PROSPERO/display_record.php?ID=CRD42017068376. 

doi:10.1016/j.jaac.2016.04.016

Centre for Reviews and Dissemination (2009) Systematic reviews: CRD's guidance for undertaking reviews in health care. University of York, Centre for Reviews \& Dissemination.

447 Claesson IM, Klein S, Sydsjo G, Josefsson A (2014) Physical activity and psychological well-being in obese pregnant and postpartum women attending a weight-gain restriction programme. Midwifery, 30(1), 11-16. doi:10.1016/j.midw.2012.11.006

Cooney GM, Dwan K, Greig CA, Lawlor DA, Rimer J, Waugh FR, Mead GE (2013) Exercise for depression. Cochrane Database Syst Rev(9), CD004366. doi:10.1002/14651858.CD004366.pub6

Da Costa D, Lowensteyn I, Abrahamowicz M, Ionescu-Ittu R, Dritsa M, Rippen N et al (2009) A randomized clinical trial of exercise to alleviate postpartum depressed mood. J Psychosom Obstet Gynaecol, 30(3), 191-200. doi:10.1080/01674820903212136

Daley AJ, Blamey RV, Jolly K, Roalfe AK, Turner KM et al (2015) A pragmatic randomized controlled trial to evaluate the effectiveness of a facilitated exercise intervention as a treatment for postnatal depression: the PAMPeRS trial. Psychol Med, 45(11) 2413-2425. doi:10.1017/S0033291715000409

Daley AJ, Winter H, Grimmett C, McGuinness M, McManus R, MacArthur, C (2008) Feasibility of an exercise intervention for women with postnatal depression: a pilot randomised controlled trial. British Journal of General Practice, 58(548), 178-183. doi:10.3399/bjgp08X277195

Egger M, Smith GD, Schneider M, Minder C (1997) Bias in meta-analysis detected by a simple, graphical test. symptomatology and anxiety. Journal of Affective Disorders. 198:pp.142-147. 
Field T (2018) Postnatal anxiety prevalence, predictors and effects on development: A narrative review. Infant Behavior and Development. 51.24-32.

471 Forsyth J, Boath E, Henshaw C, Brown H (2017) Exercise as an adjunct treatment for postpartum depression for 472 women living in an inner city-A pilot study. Health Care Women Int, 38(6), 635-639. doi:10.1080/07399332.2017.1295049

Gaston A, Cramp, A (2011) Exercise during pregnancy: a review of patterns and determinants. J Sci Med Sport, 14(4) 299-305. doi:10.1016/j.jsams.2011.02.006

Grace SL, Evindar A, Stewart DE (2003) The effect of postpartum depression on child cognitive development and behavior: a review and critical analysis of the literature. Arch Womens Ment Health, 6(4) 263-274. doi:10.1007/s00737-003-0024-6

Guyatt GH, Oxman AD, Vist GE Kunz R, Falck-Ytter Y, Alonso-Coello P, Schünemann HJ (2008). GRADE: an emerging consensus on rating quality of evidence and strength of recommendations. BMJ, 336(7650), 924-926. doi:10.1136/bmj.39489.470347.AD

Haruna M, Watanabe E, Matsuzaki M, Ota E, Shiraishi M, Murayama R, Yeo S (2013) The effects of an exercise program on health-related quality of life in postpartum mothers: A randomized controlled trial. Health, $05(03)$, 432-439. doi:10.4236/health.2013.53058

Higgins JPT, Altman DG, Gøtzsche PC, Jüni P, Moher D, Oxman AD, Sterne JAC (2011) The Cochrane Collaboration's tool for assessing risk of bias in randomised trials. BMJ, 343. doi:10.1136/bmj.d5928

Higgins J, Altman D (2008) Assessing risk of bias in included studies. In J. Higgins, \& Green, S (Ed.), Cochrane handbook for systematic reviews of interventions Cochrane book series Chichester, UK: Wiley-Blackwell. doi:10.1016/j.cct.2011.01.003 

support physical activity intervention in weight management among post-partum Latinas. BMC Public Health, 14(1), 971. doi:10.1186/1471-2458-14-971

495

496

497

498

499

500

501

502

503

504

505

506

507

LeCheminant JD, Hinman T, Pratt KB, Earl N, Bailey BW, Thackeray R, Tucker LA (2014) Effect of resistance training on body composition, self-efficacy, depression, and activity in postpartum women. Scand J Med Sci Sports. 24(2):pp.414-21.

Lewis BA, Gjerdingen DK, Avery MD, Sirard JR, Guo H, Schuver K, Marcus BH (2014) A randomized trial examining a physical activity intervention for the prevention of postpartum depression: The healthy mom trial. Mental Health and Physical Activity, 7(1), 42-49. doi:10.1016/j.mhpa.2013.11.002

Matthey S (2004). Calculating clinically significant change in postnatal depression studies using the Edinburgh Postnatal Depression Scale. Journal of Affective Disorders, 78(3) 269-272. doi:10.1016/s0165-0327(02)00313-0

McCurdy AP, Boule NG, Sivak A, Davenport MH (2017). Effects of Exercise on Mild-to-Moderate Depressive Symptoms in the Postpartum Period: A Meta-analysis. Obstet Gynecol, 129(6), 1087-1097. doi:10.1097/aog.0000000000002053

Moher D, Liberati A, Tetzlaff J, Altman DG (2009) Preferred reporting items for systematic reviews and metaanalyses: the PRISMA statement. BMJ, 339. doi:10.1136/bmj.b2535

Morrell CJ, Slade P, Warner R, Paley G, Dixon S, Walters SJ, Brugha T, Barkham M, Parry G, Nicholl J (2009) Clinical effectiveness of health visitor training in psychologically informed approaches for depression in postnatal women - pragmatic cluster randomised trial in primary care. $B M J ; 338 ; \mathrm{a} 3045$

Morrell CJ, Sutcliffe P, Booth A, Stevens J, Scope A, Stevenson M, et al (2016) A systematic review, evidence synthesis and meta-analysis of quantitative and qualitative studies evaluating the clinical effectiveness, the costeffectiveness, safety and acceptability of interventions to prevent postnatal depression. Health Technol Assess ;20(37)

Morrell CJ, Warner R, Slade P, Dixon S, Walters S, Paley G, Brugha T (2009) Psychological interventions for postnatal depression: cluster randomised trial and economic evaluation. The PoNDER trial. Health Technology Assessment, 13(30), 1-153. 
518 National Institute for Health and Care Excellence (2014) Antenatal and postnatal mental health: clinical 519 management and service guidance. Clinical guideline [CG192]. Retrieved from 520 https://www.nice.org.uk/guidance/cg192

521 Norman E, Sherburn M, Osborne RH, Galea MP (2010) An exercise and education program improves well-being 522 of new mothers: a randomized controlled trial. Phys Ther, 90(3), 348-355. doi:10.2522/ptj.20090139

523 Peterson KE, Sorensen G, Pearson M, Hebert JR, Gottlieb BR, McCormick MC (2002). Design of an intervention 524 addressing multiple levels of influence on dietary and activity patterns of low-income, postpartum women. Health 525 Educ Res, 17(5), 531-540.

526 Pope CJ, Xie B, Sharma V, Campbell MK (2013) A prospective study of thoughts of self-harm and suicidal 527 ideation during the postpartum period in women with mood disorders. Arch Womens Ment Health, 16(6), 483488. doi:10.1007/s00737-013-0370-y Vizcaino, V. (2017). Effects of exercise-based interventions on postpartum depression: A meta-analysis of randomized controlled trials. Birth, 44(3) 200-208. doi:10.1111/birt.12294

532 Putnam KT, Wilcox M, Robertson-Blackmore E, Sharkey K, Bergink, V et al (2017) Clinical phenotypes of 533 perinatal depression and time of symptom onset: analysis of data from an international consortium. Lancet 534 Psychiatry. 4(6):pp.477-485.

Robichaud KP (2009) The effects of an exercise intervention on the psychological well-being of postpartum women. Dissertation Abstracts International: Section B: The Sciences and Engineering, 69(7-B), 4124.

Ryan R, Hill S (2016). How to GRADE the quality of the evidence. Cochrane Consumers and Communication Group. Retrieved from http://cccrg.cochrane.org/author-resources.

539 Saeedi S (2013) Effect of exercise program on symptoms of postpartum depression. Iranian Journal of Obstetrics, 540 Gynecology and Infertility, 15(34) 26-31.

541 Saligheh M, Hackett D, Boyce P,Cobley S (2017) Can exercise or physical activity help improve postnatal depression and weight loss? A systematic review. Arch Womens Ment Health 20(5), 595-611. 
544 Schunemann H, Oxman A, Higgins J, Vist,G, Glasziou P, Guyatt G, \& on behalf of the Cochrane Applicability 545 and Recommendations Methods Group and the Cochrane Statistical Methods Group. (2008). Presenting results 546 and 'Summary of findings' tables. In J. Higgins \& S. Green (Eds.), Cochrane handbook for systematic reviews of 547 interventions Cochrane book series. Chichester: Wiley-Blackwell.

548 Shelton S (2015) Postpartum Depressive Symptoms: A Study of Influencing Factors and an Intervention for 549 Improvement. Dissertation, Georgia State University.

550 StataCorp (2015) Stata Statistical Software: Release 14. College Station, TX: StataCorp LP.

551 Sterne J, Egger M, Moher D (2008) Chapter 10: Addressing reporting biases. In J. Higgins \& S. Green (Eds.), 552 Cochrane handbook for systematic reviews of interventions Cochrane book series Chichester, UK: Wiley553 Blackwell.

554 Surkan PJ, Gottlieb BR, McCormick MC, Hunt A, Peterson, KE (2012) Impact of a health promotion intervention 555 on maternal depressive symptoms at 15 months postpartum. Matern Child Health J, 16(1), 139-148. 556 doi:10.1007/s10995-010-0729-x

557 Teychenne M, York R (2013) Physical activity, sedentary behavior, and postnatal depressive symptoms: a review.

558 Am J Prev Med, 45(2) 217-227. doi:10.1016/j.amepre.2013.04.004

559 Thiruppathi A, Prasana B, Mastaniah E, Vamsidhar N, Himabindu P (2014) A Structured Physical Activity and 560 Health Care Education Beats Postpartum Depression for Primipara Mothers: A Pilot Randomized Controlled 561 Trail. International Journal of Physiotherapy, 1(3), 144. doi:10.15621/ijphy/2014/v1i3/53468

562 Wisner KL, Sit DK, McShea MC, Rizzo, DM et al (2013) Onset timing, thoughts of self-harm, and diagnoses in 563 postpartum women with screen-positive depression findings. JAMA Psychiatry, 70(5), 490-498. 564 doi:10.1001/jamapsychiatry.2013.87

565 Yang CL, \& Chen CH (2018) Effectiveness of aerobic gymnastic exercise on stress, fatigue, and sleep quality 566 during postpartum: A pilot randomized controlled trial. Int J Nurs Stud, 77, 1-7. 567 doi:10.1016/j.ijnurstu.2017.09.009 